\title{
Solar photo-oxidation of recalcitrant industrial wastewater: a review
}

\author{
Ahmed Tawfik ${ }^{1}$ Mohamed Gar Alalm ${ }^{2,3} \cdot$ Hanem M. Awad ${ }^{4} \cdot$ Muhammad Islam $^{5} \cdot$ Muhammad Abdul Qyyum $^{6}$. \\ Ala'a H. Al-Muhtaseb ${ }^{6} \cdot$ Ahmed I. Osman $^{7}$ (1) $\cdot$ Moonyong Lee ${ }^{5}$
}

Received: 13 December 2021 / Accepted: 5 January 2022 / Published online: 19 February 2022

(c) The Author(s) 2022

\begin{abstract}
Conventional methods to clean wastewater actually lead to incomplete treatments, calling for advanced technologies to degrade recalcitrant pollutants. Herein we review solar photo-oxidation to degrade the recalcitrant contaminants in industrial wastewater, with focus on photocatalysts, reactor design and the photo-Fenton process. We discuss limitations due to low visible-light absorption, catalyst collection and reusability, and production of toxic by-products. Photodegradation of refractory organics by solar light is controlled by $\mathrm{pH}$, photocatalyst composition and bandgap, pollutant properties and concentration, irradiation type and intensity, catalyst loading, and the water matrix.
\end{abstract}

Keywords Recalcitrant pollutants $\cdot$ Solar photo-oxidation $\cdot$ Full-scale applications $\cdot$ Process optimization

\section{Introduction}

The treatment and reuse of industrial wastewaters are critical for the long-term management of water resources because it helps to reduce contamination in water bodies (Ateia et al. 2020). The prevalence of pollutants of emerging concern such as pesticides, perfluoroalkyl substances (PFAS), pharmaceuticals, and phenols in industrial effluents has triggered public health worries due to their extreme toxicity and biologically rebellious characteristics (Gar Alalm et al. 2021). Various human activities introduce these toxins into the

Ahmed Tawfik

prof.tawfik.nrc@gmail.com

$\triangle$ Muhammad Abdul Qyyum

m.qyyum@squ.edu.om

$\triangle$ Ahmed I. Osman

aosmanahmed01@qub.ac.uk

Mohamed Gar Alalm

m_gar_alalm@mans.edu.eg; mgaralalm@polymtl.ca

Hanem M. Awad

hanem_awad@yahoo.com

Muhammad Islam

mislamofficial01@gmail.com

Ala'a H. Al-Muhtaseb

muhtaseb@squ.edu.om

1 Water Pollution Research Department, National Research Centre, Dokki, Giza 12622, Egypt aquatic environment regularly. One of the greatest barriers to widespread adoption of water reuse is the detection of harmful organic contaminants in wastewater end-of-pipe effluent (Rueda-Marquez et al. 2020). Moreover, the toxic and recalcitrant nature can threaten the ecosystem and human health because of the contamination of water bodies (Arcanjo et al. 2018). The carcinogenic nature of these stable compounds makes the fate of these contaminants in the aquatic environment a major issue (Tolba et al. 2019). The parent pollutants are concerned, and the transformation products generated through weathering by oxidation, hydrolysis, anaerobic, or

2 Department of Public Works Engineering, Faculty of Engineering, Mansoura University, Mansoura 35516, Egypt

3 Department of Chemical Engineering, Polytechnic Montreal, Montreal, QC H3C 3A7, Canada

4 Department Tanning Materials and Leather Technology and Regulatory Toxicology Lab, Centre of Excellence, National Research Centre, El-Behouth St., Dokki, Giza 12622, Egypt

5 School of Chemical Engineering, Yeungnam University, Gyeongsan 712-749, Republic of Korea

6 Department of Petroleum and Chemical Engineering, College of Engineering, Sultan Qaboos University, Muscat, Oman

7 School of Chemistry and Chemical Engineering, Queen's University Belfast, Belfast BT9 5AG, Northern Ireland, UK 
other chemical reactions may be more toxic and carcinogenic (Chaves et al. 2019). Furthermore, some recalcitrant pollutants have colors that can absorb sunlight and reduce oxygen dissolution, and it could affect aquatic life if left untreated. Therefore, it is necessary to effectively decolor industrial effluents prior to the release to water streams (Radwan et al. 2018).

Thus, the response has been the drive to efficiently remove biorecalcitrant contaminants from industrial wastewater to detract the associated environmental problems and improve the prospect of reuse. This review study aims to develop a strategic plan for treating hazardous wastewater utilizing solar photo-oxidation, focusing on process optimization. Moreover, the comprehensive review on technical constraints, process optimization, prospective and applications of solar photo-oxidation of hazardous recalcitrant industrial wastewater are provided.

\section{Drawbacks of conventional wastewater treatments}

Biological, chemical, and physical techniques are all used to treat industrial wastewater (Parrino et al. 2019; Adel et al. 2020; Sharma and Shahi 2020; Nashat et al. 2022). Industrial effluents' physical and chemical treatments are ineffective in many cases because either the treatments fail to remove micropollutants completely or require a long retention time to reduce the pollutant concentration to the required level (Nashat et al. 2022). Moreover, conventional treatments have further drawbacks because they shift pollutants to another step, causing disposal issues. Biological methods take up more area, are less flexible in design and operation, and are sensitive to diurnal and temperature fluctuations, as well as the toxicity of some substances. Although such processes can degrade many pollutants, many others are resistant because of the complex chemical structure and high stability. Moreover, the biological treatment systems are insufficient because it depends on micro-organisms that have difficulties consuming toxic organics (Teoh and Li 2020; Fouad et al. 2021a).

Conventional chemical processes consume high dosages of chemicals and generate excessive sludge volume that requires further disposal. Physical methods such as membrane filtration processes are less investigated. Membrane processes include micro- and nanofiltration, reverse osmosis, and electrodialysis (Magdy et al. 2021). The major limitations of these methods are the fast membrane fouling and the high cost of replacement (Ling et al. 2020). Adsorption by activated carbon is another alternative for removing biorecalcitrant pollutants (Gar Alalm and Nasr 2018). However, the costs of regenerating the activated carbon are high, which reduce its applicability. Accordingly, it is recommended to use adsorption as a post-treatment for polishing the effluent of the main treatment system. The main significant drawbacks of catalysts are regeneration and collection issues from effluents for reuse.

\section{Solar irradiation availability}

The earth receives about $1.5 \times 10^{18} \mathrm{kWh}$ per year of solar irradiation (Gernjak 2006). The irradiation that reaches the ground without being blocked or absorbed is referred to as direct beam radiation; the irradiation that reaches the earth but is dispersed before arriving at the ground is known as diffuse radiation, and the total is defined as the global radiation (Gernjak 2006). Of note, the light effectively arriving at the ground level is reliant on different parameters, such as weather conditions, latitude, and time of day. Figure 1 shows the global average solar spectra that reaches the ground.

In a quest to evaluate the feasibility of solar photo-oxidation at a certain location, measurements must be performed to calculate the irradiation energy throughout the year. Many researchers interested in solar energy applications have studied the average intensity of solar irradiation on the earth. Figure 2 shows a contour map for the average solar energy per year. The abundance of solar irradiation makes it appropriate for solar energy utilization for wastewater treatment.

Natural sunlight includes ultraviolet, visible light, infrared, X-rays, and even radio waves. The spectra of almost all solar irradiation reaching the atmosphere span from $100 \mathrm{~nm}$ to about $1 \mathrm{~mm}$ (Tawfik et al. 2018; Zhao et al. 2019b). This band of irradiation energy can be classified

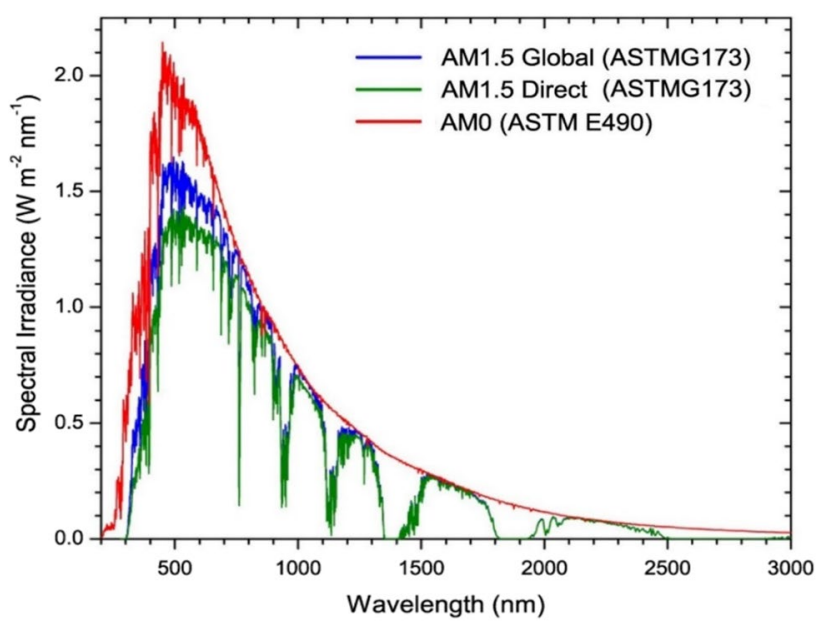

Fig. 1 Solar irradiance spectra Eke et al. (2017). The spectral irradiance versus the wavelength of the AM1.5 global (ASTMG173), AM1.5 direct (ASTMG173) and AM0 (ASTM E490). The wavelength was in the range of 0-3000 $\mathrm{nm}$. Copyrights are permitted from the publisher (Eke et al. 2017) 


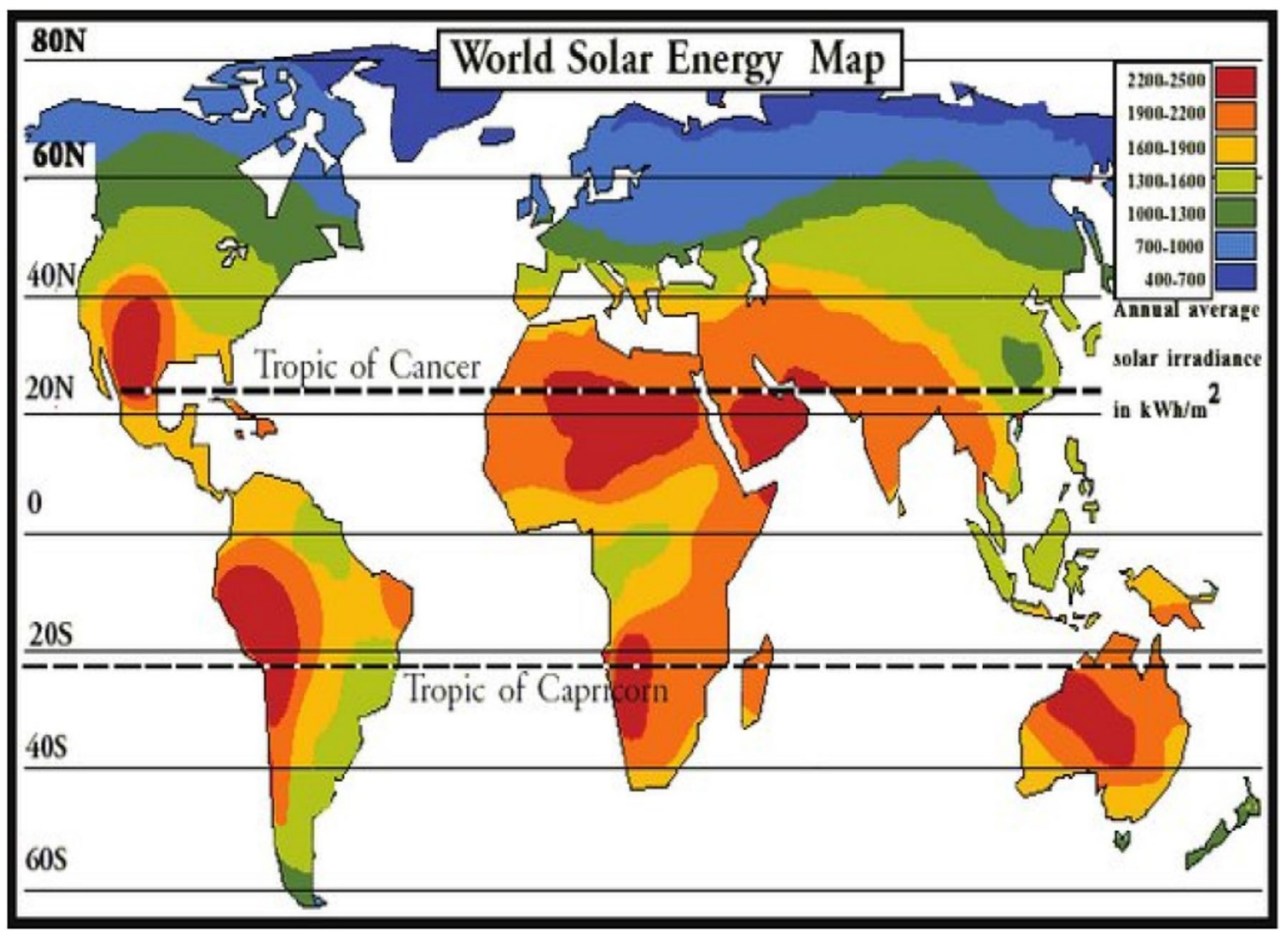

Fig. 2 World solar irradiation map (Zhang et al. 2013). The map shows the annual average solar energy distribution. The color legends described the spectral range of different frequencies on the earth

into five regions according to wavelengths (Fujiwara and Yano 2011; Chen et al. 2019; Vu et al. 2020):

a. The ultraviolet $\mathrm{C}$ (UVC) range spans a spectrum of light that occurs at a higher frequency than violet light and is therefore invisible to the human eye. Because of the atmosphere, very little of this intense light reaches Earth's surface.

b. Ultraviolet B (UVB) rays can be characterized by a 280 $315 \mathrm{~nm}$ wavelength range. Like ultraviolet rays, types $\mathrm{B}$ and $\mathrm{C}$ are absorbed heavily by the atmosphere and contribute to creating the ozone layer. The ultraviolet type B damage to DNA directly results in sunburn.

c. The ultraviolet-A ranges from 315 to $400 \mathrm{~nm}$. It was once believed that ultraviolet-A had an easier time damaging DNA than other wavelength ranges; however, it has since been demonstrated that it causes severe DNA damage.

d. This range represents the visible range of light, which spans $380-780 \mathrm{~nm}$, the smallest wavelengths of the sun's irradiance spectrum. It is also the range of the sun's total irradiance spectrum with the highest output. received from solar irradiation. Annual average solar irradiation in $\mathrm{kWh} / \mathrm{m}^{2}$. N (north), S (south)

e. The infrared range spans $700 \mathrm{~nm}$ to one million nanometers and accounts for a significant fraction of the electromagnetic energy reaching the earth.

Advanced photo-oxidation processes are mainly dependent on ultraviolet light, and hence it is recommended to use ultraviolet transparent material for the solar reactor, such as borosilicate tubes. However, some catalysts were developed to utilize a part of visible light. In ultraviolet light, the corresponding electromagnetic spectrums are ultraviolet types $\mathrm{A}, \mathrm{B}$ and $\mathrm{C}$, depending on their wavelength.

Solar advanced oxidation processes (AOPs) was successfully employed by Brienza et al. (Brienza et al. 2016) to minimize the toxicity effect of micropollutants. 2,4-Dichlorophenol and pesticides were effectively removed by flatpanel photo-reactor immobilized $\mathrm{TiO}_{2}$ (titanium dioxide) and equipped with monitor, an ultraviolet radiometer and operated with natural sunlight at spectral ranging from 310 to $400 \mathrm{~nm}$ (Janin et al. 2013). $70 \%$ of the total organic carbon (TOC) was removed wastewater industry. A pilot parabolic collector solar plant was used to degrade emerging contaminants of isoproterenol, atrazine, antipyrine, acetaminophen, 
caffeine, sulfamethoxazole, progesterone, triclosan, and diclofenac (Klamerth et al. 2009). The removal efficiencies for those contaminants varied from 45 to $78 \%$. Ahmed and Chiron (Ahmed and Chiron 2014) investigated the solar photo-Fenton for degradation of carbamazepine, which was removed by $55-82 \%$ values. Solar-based advanced oxidation treatment processes are efficient for degrading biorecalcitrant contaminants. However, the treatment costs are questionable and excess sludge generation.

\section{Advance oxidation processes for the treatment of industrial wastewaters}

Because of the limitations of traditional treatment procedures, it became necessary to develop innovative, more environmentally acceptable methods for removing refractory contaminants. As a result, substantial research efforts have been directed worldwide in recent decades to create newer, more potent, and promising ways for degrading pollutants in industrial wastewater known as advanced oxidation processes (AOPs). Advanced oxidation techniques used in chemical wastewater treatment can entirely mineralize contaminants into $\mathrm{CO}_{2}$ (carbon dioxide), water, and inorganic compounds, or at the very least, change them into more harmless chemical species. Advanced oxidation procedures entail the production of enough hydroxyl radicals to oxidize organic pollutants (Gar Alalm et al. 2015a; Su et al. 2021). Although additional species may contribute to degradation, the major oxidant species appears to be superoxide and hydroxyl radicals, which are unstable and highly reactive in most circumstances (Monteagudo et al. 2020; Wu et al. 2021a). These sophisticated oxidation techniques can be divided into homogeneous and heterogeneous. Energyconsuming and non-energy processes are two different types of homogeneous processes. Figure 3 displays a variety of advanced oxidation methods that are now being researched for use in treating wastewater.

\section{Heterogeneous photocatalysis}

Photocatalysts like titanium dioxide, tungsten trioxide, and metal-organic-frameworks (MOFs) are used in heterogeneous photocatalytic oxidation (HPO) processes, showing promising results in the breakdown of organic contaminants and the production of more biodegradable and less hazardous compounds (Bavykina et al. 2020; Ahmadijokani et al. 2021; Zorainy et al. 2021). This technique is based on forming hydroxyl radicals
Fig. 3 Classification of advanced oxidation processes (AOPs). The classification is based on heterogeneous, which involve photocatalytic ozonation, catalytic ozonation and heterogeneous photocatalysis processes. Furthermore, the homogeneous processes are classified with and without energy. The energy-oriented processes include electrical, ultrasound and ultraviolet energy processes. $\mathrm{O}_{3}$ (ozone), $\mathrm{H}_{2} \mathrm{O}_{2}$ (hydrogen peroxide), $\mathrm{Fe}^{2+}$ (Ferrous cation)

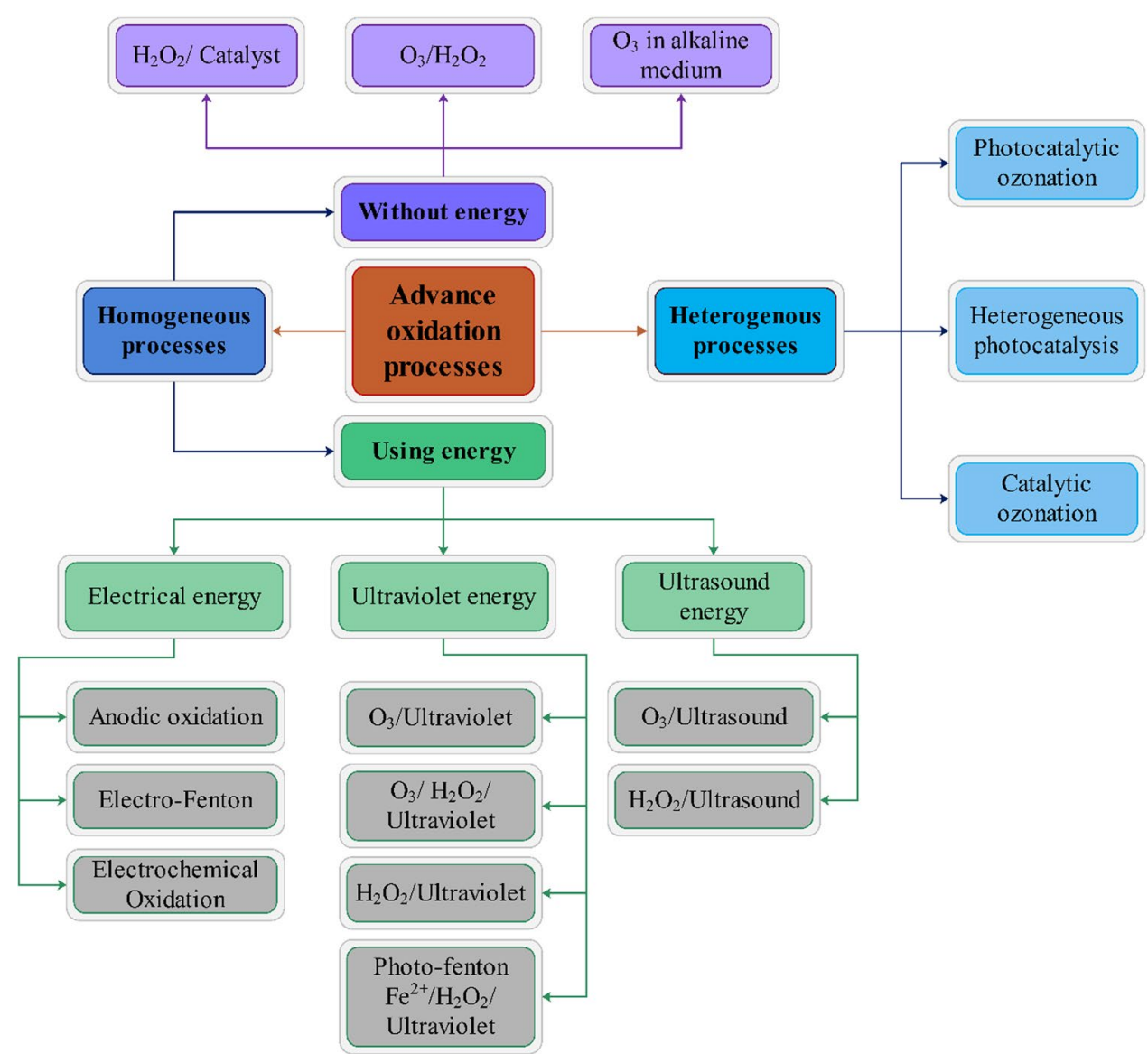


in situ under ambient settings, which transform a wide range of harmful chemical molecules, including those that are non-biodegradable, into comparatively benign transformation products such as $\mathrm{CO}_{2}$ and $\mathrm{H}_{2} \mathrm{O}$. The oxidation of persistent compounds relies on a triple action of a semiconductor photocatalyst, light irradiation source, and oxidizing agent. Ultraviolet and visible radiation from the sun can also power the process. On the earth's surface, $0.2-0.3$ mol photons $\mathrm{m}^{-2} \mathrm{~h}^{-1}$ of solar ultraviolet radiation is reached, ranging between 300 and $400 \mathrm{~nm}$, with an average energy of $20-35 \mathrm{Wm}^{-2}$. This demonstrates that sunshine can be a cost-effective and ecologically beneficial illumination source. (Ahmed et al. 2011; Zhao et al. 2022). Consequently, there has been much interest in developing effective photocatalytic wastewater remediation for full-scale applications. Solar photocatalytic oxidation of insecticides, medicines, and phenols has recently been deeply explored, even though heterogeneous photocatalysis has appeared in various forms. The wastewater $\mathrm{pH}$, categories of photocatalyst and structure, pollutant concentration and type, light intensity, photocatalyst dosage, other wastewater constituents, and solvent kind all play a role in photocatalytic degradation of refractory organics (Antonopoulou et al. 2021; Samy et al. 2021; Yang et al. 2021c; Wang et al. 2022b). However, low efficiency resulting from poor visible-light capturing catalysts, photo-reactor design, catalyst recovery and reuse, the formation of hazardous intermediates, and concerns about catalyst deactivation are all stated to be important downsides (Assadi

et al. 2021; Chen et al. 2021; Su et al. 2021; Yang et al. 2021c; Gar Alalm et al. 2021).

In the heterogeneous photocatalysis ultraviolet/titania method (Fig. 4), ultraviolet light range $\lambda<400 \mathrm{~nm}$ is used for illumination, and titanium dioxide semiconductor acts as a catalyst. Titanium dioxide stands out among other semiconductors because of its large surface area, regular shape and size of particles, high stability, and ability to use sunlight as a light source (Fatima and Kim 2021; Mohanta and Ahmaruzzaman 2021; Wu et al. 2021b). Photons with energies greater than the bandgap energy excite valence band electrons in the photocatalysis oxidation process, boosting interactions with organic contaminants (Mohanta and Ahmaruzzaman 2021; Huang et al. 2021). A positive hole $\left(\mathrm{h}^{+}\right)$is generated in the valence band, while in the conduction band, an electron (e-) is generated when the catalyst active surface is illuminated with enough energy (Zhu et al. 2021). The positive hole produces hydroxyl radicals by oxidizing either the organic contaminant or $\mathrm{H}_{2} \mathrm{O}$. The oxygen deposited on the semiconductor surface is reduced by the electron in the conduction band. The reactions that occur when ultraviolet light activates titanium oxide are as follows: (Ahmed et al. 2011).

$$
\begin{aligned}
& \mathrm{TiO}_{2}+h v \rightarrow \mathrm{e}^{-}+\mathrm{h}^{+} \\
& \mathrm{e}^{-}+\mathrm{O}_{2} \rightarrow \mathrm{O}_{2} \cdot{ }^{-}
\end{aligned}
$$

Fig. 4 Principles of titanium dioxide photocatalysis (Ahmed et al. 2011). It shows the photoreduction and photo-oxidation processes, where the excitation and recombination occur between the conduction band (CB) and valence band (VB) of the titania catalyst. $\mathrm{h}^{+}$(proton), $\mathrm{e}^{-}$(electron), $\mathrm{O}_{2}$ (oxygen), $\mathrm{H}_{2} \mathrm{O}$ (water), $\mathrm{CO}_{2}$ (carbon dioxide), $\mathrm{H}_{2} \mathrm{O}_{2}$ (hydrogen peroxide), UV (ultraviolet), R (functional group)

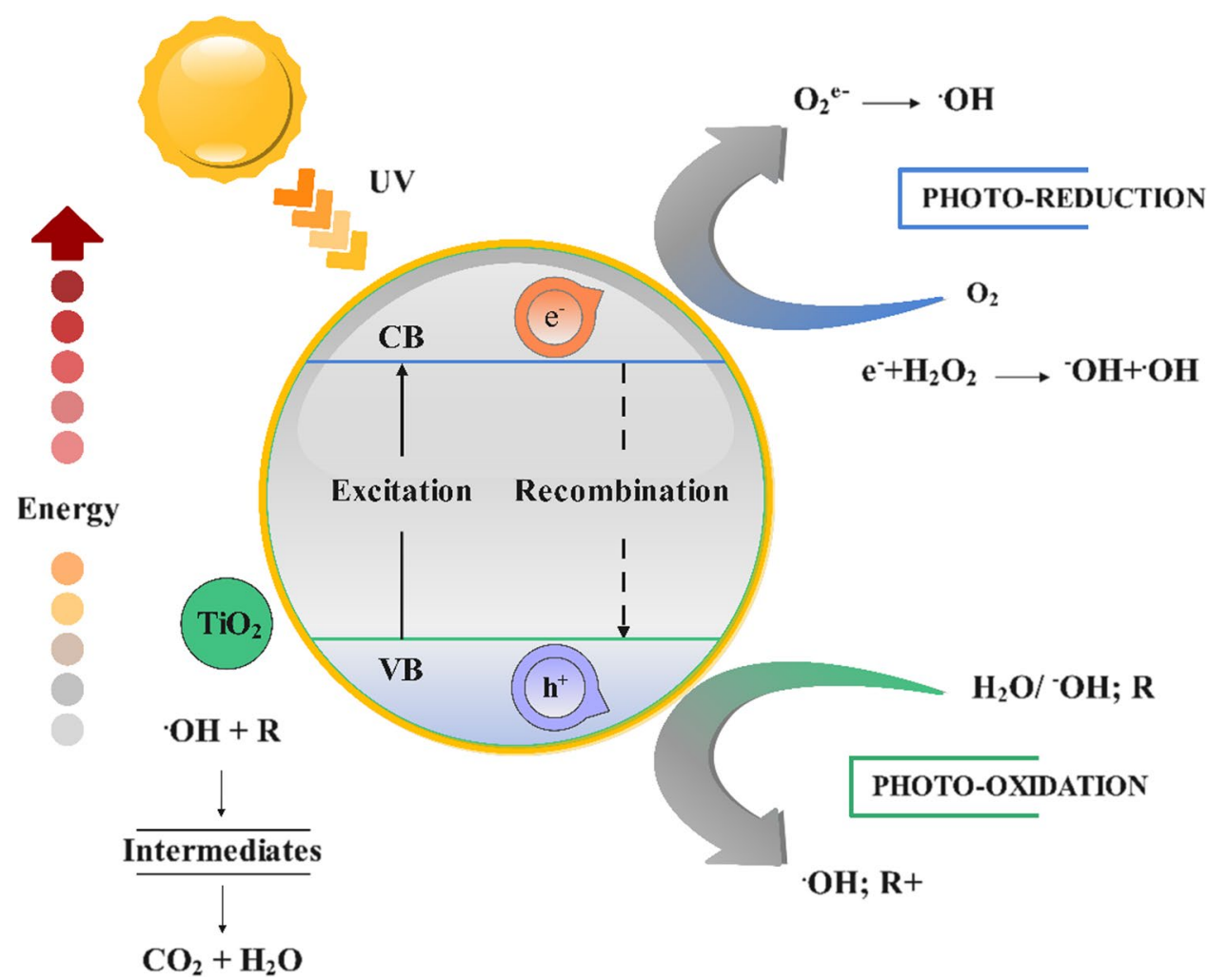


$\mathrm{h}^{+}+\mathrm{H}_{2} \mathrm{O} \rightarrow \cdot \mathrm{OH}+\mathrm{H}^{+}$

$\mathrm{R}+\cdot \mathrm{OH} \stackrel{\text { yields }}{\longrightarrow}$ degradation

$\mathrm{R}+\mathrm{h}^{+} \stackrel{\text { yields }}{\longrightarrow}$ oxidation

$\mathrm{R}+\mathrm{e}^{-} \stackrel{\text { yields }}{\longrightarrow}$ reduction

Because the bandgap of $\mathrm{ZnO}$ (zinc oxide) is similar to that of titanium dioxide, $3.2 \mathrm{eV}$, under intense sunlight, it has been found to be as reactive as titanium dioxide (Heidari et al. 2020). Different metal oxide semiconductors, such as $\mathrm{ZrO}_{2}$ (zirconium oxide), $\mathrm{LaVO}_{4}$ (lanthanum vanadate), $\mathrm{WO}_{3}$ (tungsten trioxide), and $\mathrm{ZnO}$, were also studied for their ability to degrade organic pollutants (Martín-Sómer et al. 2019; Samy et al. 2020a; Yang et al. 2021c; Hu et al. 2021). A pseudo-first-order model can explain the removal rates of organic pollutants at low substrate concentrations (Lewis et al. 2020; Martínez-Pachón et al. 2021).

Many efforts were devoted to immobilizing titanium dioxide particles on various supports to improve catalytic activity and facilitate the collection of a photocatalyst. (Gar Alalm et al. 2014; Samy et al. 2020d, b). Due to low particle suspension and restricted mass transfer of the contaminant and catalyst, titanium dioxide-coated plates showed slower degradation rates (Hinojosa-Reyes et al. 2013; Amiri et al. 2016). Many research works have demonstrated that supporting the semiconductor on activated carbon as strong adsorbents can be more efficient and easier for catalyst collection (Matos et al. 2009; Bardestani et al. 2019; Chávez et al. 2020).

Although activated carbon does not exhibit a catalytic role, it boosts the catalytic performance of titanium dioxide due to higher contaminant attraction to titanium dioxide/ activated carbon. As adsorption increases, the concentration of pollutants near titanium dioxide rises (Gar Alalm et al. 2015a). Because of its well-developed micropores, high surface area, and sorption capacity, powdered activated carbon is commonly exploited to adsorb different kinds of pollutants. On titanium dioxide/activated carbon composites, activated carbon behaves like a hub for pollutants to attach before being delivered to the breakdown site (Yao et al. 2019).

\section{Factors affecting the degradation of hazardous contaminants by photocatalysis}

By integrating relevant electronic bands in one composite, hetero-structured photocatalysts attempt to facilitate the separation of photo-excited electron-hole pairs by multiple transfer paths (Antonopoulou et al. 2021). With appropriate band edge placements, effective electron and hole transfer from different semiconductors can considerably reduce energy-wasting photo-induced electron-hole pair recombination and enhance charge carrier lifetime, boosting photocatalytic efficiency. Many researchers have found that the catalytic breakdown of PFAS (Perfluoroalkyl substances), pharmaceuticals, and other resistant pollutants is heavily influenced by initial $\mathrm{pH}$, photocatalyst type and band structure, initial pollutant concentration, irradiation type, catalyst dosage, wastewater matrix, and catalyst calcination temperature, all of which are discussed in this section (Sühnholz et al. 2021; Yuan et al. 2022). A wide spectrum of newly invented heterojunctions will be addressed in this section, emphasizing improving their photoactivity for industrial wastewater remediation.

\section{Type and composition of the catalyst}

Titanium dioxide photocatalytic performance is influenced by surface functional groups and crystal properties such as crystal composition, porosity, band structure, and presence of hydroxyl functional groups. (Ahmed et al. 2011; Samy et al. 2020c). Particle size is critical in photocatalytic processes because it defines the specific surface area of a catalyst, which is directly connected to its efficiency. Numerous commonly produced catalysts have been studied in an aqueous environment for photocatalytic degradation of different chemical molecules (Rafaely et al. 2021; Zhang et al. 2021). The specifications and features among some commercial titanium dioxide samples are listed in Table 1. The photocatalyst titanium dioxide Minerals, Degussa P25, which is commercially available, was exploited in many applications. titanium dioxide with different phases compositions, such as Hombikat ultraviolet 100, PC 10, PC 50, Rhodia, and Travancore Titanium Products, are often tested for hazardous compound breakdown (Ahmed et al. 2011). Due to the particular area, such as equivalent to $50 \mathrm{~m}^{2} / \mathrm{g}$ and small particle size such as equivalent to $20 \mathrm{~nm}, \mathrm{P} 25$ include 75 percent anatase and 25 percent rutile. It has been established that dye degradation occurs faster in the presence of P25 than in other photocatalysts. Photocatalyst efficiency was found to be in this order: For the breakdown of different pesticide and herbicide compounds, P25 > ultraviolet $100>$ PC500 > TTP (Travancore titanium products) (Doll and Frimmel 2004; Lebedev et al. 2016).

Because these parameters can influence the sorption behavior of a contaminant and its transformation products, as well as the lifetime and charge recombination, differences in the Brunauer-Emmett-Teller (BET) surface, impurities, lattice structure, or existence of hydroxyl functional groups are likely to influence the photodegradation rates (Kumar et al. 2020; Antonopoulou et al. 2021; Qin et al. 2021). 
Table 1 Composition of different titanium dioxide catalysts. The table shows the surface area, the typical size of crystals, along with the crystal structure

\begin{tabular}{lclll}
\hline Catalyst & $\begin{array}{l}\text { Surface area } \\
\left(\mathrm{m}^{2} / \mathrm{g}\right)\end{array}$ & $\begin{array}{l}\text { Typical size of } \\
\text { crystal }(\mathrm{nm})\end{array}$ & Crystal structure & Reference \\
\hline P25 & 50.0 & $20-25$ & $\begin{array}{l}75 \% \text { anatase } \\
25 \% \text { rutile }\end{array}$ & Singh et al. (2007) \\
PC500 & 287 & $5.0-10.0$ & Anatase & Singh et al. (2007) \\
Ultraviolet 100 & 250.0 & 5 & Anatase & Singh et al. (2007) \\
TTP & 9.8 & - & - & Singh et al. (2007) \\
PC 10 & 10.0 & $65-75$ & Anatase & Enríquez and Pichat (2006) \\
PC 50 & 54.0 & $20-30$ & Anatase & Enríquez and Pichat (2006) \\
Rhodia & 150.0 & - & Anatase & Enríquez and Pichat (2006) \\
\hline
\end{tabular}

TTP (Travancore titanium products), UV (Ultraviolet), PC (Photocatalyst), P25 (75\% anatase, 25\% rutile)
Ultraviolet 100 has a strong light sensitivity because of the rapid transfer of electrons, while Degussa P25 has a higher photocatalytic activity which is imputed to slower recombination of charges (Ahmed et al. 2010). Titanium dioxide Degussa (p25) was tested in many studies for phenol degradation and revealed a good degradation efficiency, especially for phenol concentration less than $100 \mathrm{mg} / \mathrm{L}$ (Carbajo et al. 2018; Bueno-Alejo et al. 2019). In addition, titanium dioxide showed a good degradation for many pharmaceuticals types that may exist in industrial wastewater (Gar Alalm et al. 2016; Fathinia et al. 2020; Giannakis et al. 2021; Fouad et al. 2021b).

\section{Concentrations of hazardous contaminants}

The rate of titanium dioxide photocatalytic response has been shown to be dependent on the content of wastewater pollutants in previous studies (Garcia-Muñoz et al. 2020b; Serrà et al. 2021). A difference in the number of wastewater pollutants will require varied irradiation periods to obtain optimum degradation with specific operational parameters. Because photocatalysis reactions are photonic in nature, an overly high concentration of organic substances has been shown to gradually block the titanium dioxide surface and impair light absorption, resulting in photocatalyst inactivation (Zhao et al. 2019a; Gora and Andrews 2019; Qin et al. 2021; Yang et al. 2021b). Many investigations discovered that as the initial concentration of the pollutant was raised, the photocatalytic degradation efficiency declined (Dong et al. 2022; Pan et al. 2022; Yue et al. 2022). Parida and Parija (2006) explored the role of a relatively high starting contaminant concentration such as $2-15 \mathrm{~g} / \mathrm{L}$, on phenol removal under different irradiation sources. Under solar irradiation, the degradation efficiency fell from 100 percent to $60 \%$ by raising the pollutant concentration. The degradation decreased from 94 to 52 percent under ultraviolet light with raising initial concentrations.

Under visible light, the deterioration was reduced from 95 to 50\% (Parida and Parija 2006). Lathasree et al. studied the effect of beginning concentrations ranging from 40 to $100 \mathrm{ppm}$ on the catalytic oxidation of phenol by $\mathrm{ZnO}$. Photodegradation was initially accelerated at low concentrations, but the degradation rate decreased as concentrations rose. The breakdown was discovered to follow first-order kinetics. The degradation of chlorophenols was shown to grow in the 40-60 ppm concentration range, and then it was reduced as the concentration increased (Lathasree et al. 2004). Several studies have found that many molecules are attracted to the photocatalyst at higher initial concentrations of pollutants (Chatzimpaloglou et al. 2022; Li et al. 2022b; Xu et al. 2022). As a result, the oxidant species essential for pollutant breakdown, such as the hydroxyl radical, rise. However, the generation of hydroxyl radicals for given light intensity, catalyst quantity, and exposure time are the same (Jin et al. 2022; Sun et al. 2022). As a result, the generated hydroxyl radicals may be insufficient for complete breakdown at greater pollutant concentrations (Ren et al. 2022; Wang et al. 2022e). Consequently, the rate of contaminant breakdown slows at higher concentrations (Ren et al. 2022; Wang et al. 2022e). Furthermore, as the substrate concentration rises, intermediates are produced, which may adsorb on the catalyst's surface (Kim et al. 2022). Slow diffusion of produced intermediates from the catalyst surface can deactivate active sites on the photocatalyst, slowing the degradation rate at low concentrations (Bai et al. 2022).

On the other hand, as anticipated by first-order kinetics, the number of active sites would not be a major limitation, and the degradation rate will be related to the reaction mixture (Ahmed et al. 2011). In the case of combustion generated titanium dioxide and P25, Priya and Madras (2006) investigated the effect of starting concentrations ranging from 10 to $76 \mathrm{ppm}$ on the photocatalytic oxidation of 2,4-dinitrophenol. At $76 \mathrm{ppm}$, the most significant deterioration was seen (Priya and Madras 2006). The photocatalytic breakdown of pharmaceuticals has shown similar tendencies (Pattappan et al. 2022; Ramalingam et al. 2022). 


\section{Light intensity and wavelength}

Based on the kinds of photocatalysts utilized, crystal structure, anatase to rutile ratio, and any condition of photocatalyst adjustments, the photochemical impacts of radiation bulbs with varied wavelength emitting spans have a significant effect on the photocatalytic reaction rate (Wang et al. 2022a; Xie et al. 2022). A light wavelength of $380 \mathrm{~nm}$ is adequate for photon activity when using commercial Degussa P-25 titanium dioxide, which has an anatase 70/80: 20/30 crystalline ratio (Chong et al. 2010). The light intensity determines how much light is absorbed by the semiconductor catalyst at a specific wavelength. The pace of commencement of the photochemical process for photocatalysis electron-hole generation is greatly influenced by the light intensity (Abidi et al. 2022; Mafa et al. 2022). The amount of light intensity within the reactor usually influences the total pollutant transformation and destruction efficiency (Abidi et al. 2022; Li et al. 2022d; Mafa et al. 2022; Xiong et al. 2022).

As a result, several studies have examined the relationship between pollutant degradation rate and light intensity for various organic contaminants (Atun et al. 2022; Latif et al. 2022). While the reaction rate was shown to be square root dependent on the light intensity in some circumstances, the two variables were found to have a linear relationship in others (Aliste et al. 2022; Zhang et al. 2022). Puma and Yue used ultraviolet-A alone and ultraviolet-A, B, and C irradiation to investigate the influence of wavelength range on the photodegradation of 2-chlorophenol. Compared to ultraviolet-A radiation, ultraviolet-ABC radiation significantly boosted the 2-chlorophenol breakdown and mineralization (Li Puma and Yue 2002). Under ultraviolet-ABC light, the initial rate of 2-chlorophenol deterioration was found to be 1.8 times faster, and 2-chlorophenol degradation reached 98 percent in $20 \mathrm{~min}$. The photon flux, which was estimated to be 1.56 times higher than ultraviolet type A radiation, was linked to the enhanced degradation rate with ultraviolet-ABC radiation. Photocatalysis, photonics, and potential interactions due to combined photolysis and photocatalysis enhanced the rate improvement. On clear and gloomy periods, Kaneco et al. studied the effect of illuminance on the sun photodegradation of bisphenol A in waters by titanium dioxide. With only a little increase in the intensity up to $35 \mathrm{~W} / \mathrm{m}^{2}$, the degradation performance can be improved quickly (Kaneco et al. 2004). The influence of ultraviolet light intensity ranges $20-400 \mathrm{~W}$ on phenol photodegradation was investigated by Chiou and Juang. The first-order kinetics were followed in all the reactions. With a light intensity of $20 \mathrm{~W}, 100 \mathrm{~W}$, and $400 \mathrm{~W}$, the degradation rate constants in the ultraviolet and titanium dioxide system are 8.3103, 0.012 , and $0.031 \mathrm{~min}^{-1}$, respectively (Chiou and Juang 2007). The apparent first-order rate constant and irradiation energy have an acceptable linear association under the investigated conditions. The hydroxyl radical generation is aided by increasing light intensity, which improves the degradation rate (Chiou and Juang 2007).

\section{$\mathrm{pH}$}

The electrostatic state of photocatalyst particles, size of crystals, and band structure are all affected by the solution $\mathrm{pH}$ in the photocatalytic system. Because of the electro-properties of titanium dioxide, the change of the solution $\mathrm{pH}$ affects the surface charge (Kim et al. 2022; Shah et al. 2022). Numerous research works have investigated the point of zero charges of titanium dioxide to study the impact of $\mathrm{pH}$ on photodegradation activity. (Deng et al. 2019; Kovacic et al. 2019). Depending on the catalysts used, the point of zero charges is a pH range of 4.5-7.0, where the surface charge of the catalyst is neutral. Because there is no electrostatic force at zero charges of the catalyst, the attraction of pollutants to the catalyst surface is limited (Marinho et al. 2017). When functioning at $\mathrm{pH}$ point of zero charges (titanium dioxide), the catalyst's surface charge becomes positively charged, attracting negatively charged molecules electrostatically over time. Such polar affinities between titanium dioxide and charged pollutant molecules can increase adsorption onto the photon-induced catalyst surface for future catalytic reactions (Ambrosio et al. 2017; Kovacic et al. 2019). This is very important when anionic organic molecules are present in low concentrations. The catalyst surface will be negatively charged at $\mathrm{pH}>$ point of zero charges (titanium dioxide), repelling anionic chemicals in the water. The surface charge density of the titanium dioxide catalyst is affected by $\mathrm{pH}$ (Chong et al. 2010; Gar Alalm et al. 2015b). Organic pollutants can be protonated or deprotonated depending on the $\mathrm{pH}$ of the solution. Protonated compounds are perhaps more persistent than their parent structures when exposed to ultraviolet radiation (Chatzimpaloglou et al. 2022; Pattappan et al. 2022). As a result, the $\mathrm{pH}$ of wastewater may significantly impact pollutant adsorption and photocatalytic oxidation.

In acidic conditions, the positive charge on the catalyst sites increases as the $\mathrm{pH}$ decreases. When the $\mathrm{pH}$ is higher than the point of zero charges, the negative charge at the catalyst surface rises. Furthermore, the water $\mathrm{pH}$ influences the production of reactive oxidant species via the interaction among hydroxide ions and generated holes on the catalyst active sites. Positive holes are the most important oxidation processes at low $\mathrm{pH}$, although hydroxyl radicals are the major species at neutral and basic conditions (Berkani et al. 2022; Kim et al. 2022). Because there are more accessible hydroxyl ions on the titanium dioxide surface, it is expected that the formation of hydroxyl radicals will be higher. With changes in solution $\mathrm{pH}$, the electrostatic attractive or 
repulsive forces between the catalytic surface and the ionic states of pollutants might change, resulting in facilitation or inhibition of organic pollutant degradation when catalyst particles are present (Wang et al. 2022d). As a result, the best $\mathrm{pH}$ for photodegradation is determined by both the photocatalyst and the pollutant. Table 2 shows the optimal $\mathrm{pH}$ of various pollutants and catalysts described earlier in the literature. As a result, the process's degrading efficiency will logically increase at high $\mathrm{pH}$.

\section{Catalyst loading}

In a truly heterogeneous catalytic regime, the catalyst concentration in the photocatalytic process for wastewater treatment systems affects the total photocatalysis reaction rate (Chen et al. 2022). Several investigations have found that due to blocking and scattering of light scattering and screening effects of turbidity, the photocatalytic degradation rate first improved by photocatalyst loading but declined if excessive amounts were added (Liang et al. 2022; Wang et al. 2022f). At high solids concentrations, the tendency for agglomeration, such as particle-particle contact, rises, reducing the active sites exhibited to irradiation and, as a result, decreasing the photodegradation rates ( $\mathrm{Li}$ et al. 2022a; Zaitsev and Astapov 2022). Even though the density of active particles in water increases as the catalyst is loaded, it appears that a point has been reached when light penetration is impeded because of the turbidity associated with the suspended catalyst. The optimal photocatalyst amount for photocatalytic oxidation is achieved when these two opposing phenomena coexist. A higher catalyst amount than the optimal will cause an irregular illumination of the catalyst, which will slow down the reaction rate (Gar Alalm et al. 2018). A linear relationship exists until the reaction rate accelerates and becomes irrelevant to catalyst loading. This is due to the photocatalytic reactor's shape and operating circumstances, where the surface activity is triggered by light photon absorption (Pattappan et al. 2022; Ramalingam et al. 2022). Any photocatalytic reaction must include a dosage lower than the saturation threshold of the photocatalyst utilized to avoid excess catalyst and for efficient photon absorption.

The impacts of catalyst loadings on reaction rates have been widely investigated in the literature (Dehkordi and Badiei 2022; Li et al. 2022b; Pan et al. 2022; Wang et al. 2022c). Because the operating configuration, irradiation fluxes, strength, and wavelengths used were all different, the results are mostly unrelated, and a direct comparison is impossible. According to reports, the optimal catalyst loading for photo-mineralization and photo-disinfection varies depending on the size of the photo-reactor (Fouad et al. 2021c). Furthermore, in terms of effective photon absorption and water flow hydrodynamics, the diameter of the photo-reactor must be determined (Ramalingam et al. 2022; Wang et al. 2022a). A steady-state residence time can be achieved with a uniform flow region, but turbulence flow can remove catalyst deposition or reaction dead zones (Zapata et al. 2010). The turbulent flow was impossible in reactors with diameters lower than 20-25 mm, while sizes bigger than 50-60 $\mathrm{mm}$ were unfeasible. Because large diameters often have lower saturated catalyst loading and efficiency, the amount of catalyst should be evaluated in this case. Prior to introducing the reactor system, the titanium dioxide catalysts are usually uniformly mixed with the desired effluent (Bai et al. 2022; Xu et al. 2022). The tight adsorption of organics onto the catalyst's surface results in a decreased initial concentration of organic contaminants in the catalyst

Table 2 Optimum $\mathrm{pH}$ values for the degradation of various contaminants, using various light and catalyst types, including titania, zinc oxide and other catalysts. The optimum $\mathrm{pH}$ ranges from 3 to 11

\begin{tabular}{llllll}
\hline Contaminants & Light type & Catalyst & Investigated pH & Optimal pH & Reference \\
\hline Carbofuran (Pesticide) & Ultraviolet & $\mathrm{TiO}_{2}$ & $4-9$ & 7 & Hameed et al. (2009) \\
Isoproturon (Pesticide) & Solar light & $\mathrm{TiO}_{2}$ & $3-10$ & 7 & Phanikrishna Sharma et al. (2009) \\
Carbofuran (Pesticide) & Solar light & $\mathrm{TiO}_{2}$ & $3-9$ & 7.6 & Lopez-Alvarez et al. (2011) \\
Methamidophos (Pesticide) & Ultraviolet & $\mathrm{TiO}_{2}$ & $2-12$ & 12 & Wei et al. (2009) \\
Diazinon (Pesticide) & Ultraviolet & $\mathrm{ZnO}^{2}$ & $0.5-4$ & 3 & Daneshvar et al. (2007) \\
Dipterex (Pesticide) & Ultraviolet & $\mathrm{TiO}_{2} / \mathrm{Ni}$ & $1-7$ & 6 & Fang et al. (2012) \\
Phenol & Ultraviolet & $\mathrm{ZnO}$ & $4-9$ & 4 & Lathasree et al. (2004) \\
Phenol & Ultraviolet & $\mathrm{TiO}_{2}$ & $3-11$ & 3 & Kartal et al. (2001) \\
Phenol & Ultraviolet & $\mathrm{TiO}_{2} / \mathrm{AC}$ & $2-12$ & 4.2 & Lam et al. (2010) \\
Carbendazim (Fungicide) & Ultraviolet & $\mathrm{TiO}_{2}$ & $3-9$ & 11 & Saien and Khezrianjoo (2008) \\
Amoxicillin (Pharmaceutical) & Ultraviolet & $\mathrm{ZnO}_{\text {anO }}$ & $4-11$ & 11 & Elmolla and Chaudhuri (2010) \\
Ampicillin (Pharmaceutical) & Ultraviolet & $\mathrm{ZnO}$ & $4-11$ & 11 & Elmolla and Chaudhuri (2010) \\
Claxocillin (Pharmaceutical) & Ultraviolet & $\mathrm{ZnO}$ & $4-11$ & Elmolla and Chaudhuri (2010) \\
\hline
\end{tabular}

$\mathrm{TiO}_{2}$ (titanium oxide), $\mathrm{ZnO}$ (zinc oxide), $A C$ (activated carbon), $\mathrm{Ni}$ (nickel) 
dark homogenization (Chatzimpaloglou et al. 2022; Jin et al. 2022; Li et al. 2022b). Wei et al. explored the effect of titanium dioxide loading on methamidophos degradation. The photodegradation efficiency is linearly proportional to the catalyst mass when the illumination time is $30 \mathrm{~min}$. The photocatalytic degradation efficiency of methamidophos improved from 16.6 percent to 75.1 percent as the photocatalyst loading raised from 2.0 to $12.0 \mathrm{~g} / \mathrm{L}$. When the amount of titanium dioxide in the solution exceeds $12.0 \mathrm{~g} / \mathrm{L}$, the efficiency drops marginally (Wei et al. 2009). As the number of titanium dioxide particles grows, many photons and methamidophos molecules are consumed.

As a consequence of the increased total surface area for pollutant adsorption, raising titanium dioxide concentration can improve degradation efficiency. Light blocking and scattering may occur if the catalyst concentration is increased over $12.0 \mathrm{~g} / \mathrm{L}$. The extra titanium dioxide photocatalyst causes opacity in the suspension, preventing illumination of the catalyst farthest in solution (Wei et al. 2009). Daneshvar et al. studied the influence of loading $\mathrm{ZnO}$ on diazinon photodegradation. The $\mathrm{ZnO}$ loading was varied between 25 and $200 \mathrm{mg} / \mathrm{L}$ while all other parameters remained constant. Experiments with various concentrations of $\mathrm{ZnO}$ nanopowder revealed that the photocatalytic degradation efficiency rose with an increase in $\mathrm{ZnO}$ nanopowder concentration up to $150 \mathrm{ppm}$, beyond which an increase in catalyst loading had no discernible effect on the degradation. The active sites on the catalyst surface and ultraviolet light penetration into the solution were used to explain this discovery. The overall active surface area expands when the catalyst dosage is raised. It was also noted that when the turbidity of the suspension grows, ultraviolet light penetration reduces due to the rising scattering effect, resulting in a decrease in the photo-activated volume of the suspension (Jin et al. 2022; Ren et al. 2022). Furthermore, maintaining a homogenous suspension at high catalyst concentrations is difficult (Chatzimpaloglou et al. 2022; Xu et al. 2022).

\section{Catalyst immobilization}

Since discovering the photo-electrocatalytic influence on water splitting with a titanium dioxide electrode, numerous studies have been conducted to synthesize titanium dioxide catalysts on various scales, characterize their physical properties, and determine their photo-oxidation performances due to the surface-oriented essence of photocatalysis reactions (Dong et al. 2022; Li et al. 2022b; Yue et al. 2022). The nanoscale titanium dioxide catalyst provides a high surface-area-to-volume ratio, which aids in efficient charge separation and trapping at the physical surface. Furthermore, as compared to bulk catalysts, the light opaqueness of these nanoscale catalysts has been observed to have an enhanced oxidation performance (Harijan et al. 2022; Zhang et al. 2022).

Until now, the most ubiquitous applied photocatalyst in water and wastewater treatment research is the P-25 titanium dioxide catalyst. This catalyst is utilized as a benchmark for comparing photocatalytic activity under various treatment circumstances (Gar Alalm et al. 2021). P-25 titanium dioxide fine particles have often been administered in the form of slurry. When the titanium dioxide catalyst is suspended, this is usually linked to the high volumetric production rate of oxidant species, which is relevant to the area of active sites (Khan et al. 2019). Catalyst attachment into a large inert substrate, on the other hand, limits the number of catalyst active sites and increases mass transfer constraints. When the catalysts are immobilized, photon transmission may not contact all targets for photonic excitation, making the operation more challenging. As a result, titanium dioxide catalysts in the slurry form are frequently used (Cerrato et al. 2019; Garcia-Muñoz et al. 2020a).

Many researchers investigated immobilizing the catalyst on a support material to improve the ability of recollection the catalyst after the reaction or enhancement of photocatalytic activity by higher adsorption capacity supports (Chijioke-Okere et al. 2021; Lima et al. 2022; Matiazzo et al. 2022). So far, attempts to immobilize these composite films on supports, including glass beads, glass, and stainless steel, have been developed to degrade organic contaminants by photocatalysis (Lu and Zhang 2022; Valadez-Renteria et al. 2022; Zhou et al. 2022). However, the activity for the decomposition of organics by other sorbents as a supporter of photocatalyst still remains unreported. These sorbents often used include silica gels, activated carbon, zeolites, and clays. The sorbents are selected to be easily suspended by air bubbling or mechanical stirring. Because of its high adsorbability and specific area, activated carbon (AC) is a suitable alternative among these sorbents (Zeng et al. 2021; Huang et al. 2022). Additionally, due to activated carbon's strong adsorptive capacity for organic molecules, adding titanium dioxide to it could have some favorable benefits, as well as solve the problem of establishing optimal adsorption capacity of the adsorbate species on the adsorbent to boost the photo-oxidation performance (Rayati et al. 2021; Yang and Luo 2021).

Although activated carbon does not exhibit photodegradation activity, it boosts the photocatalytic reaction of titanium dioxide due to higher contaminant adsorption on titanium dioxide and activated carbon. As adsorption increases, the concentration of pollutants near titanium dioxide rises $(\mathrm{Li}$ et al. 2022c; Tang et al. 2022). Because of its well-developed pore structure, high surface area, and sorption capacity, powdered activated carbon (PAC) is widely seen as an adsorbent for different kinds of pollutants. In activated carbon loaded catalysts, activated carbon can act as a center for organic 
molecules to adsorb until transported to the breakdown center (Li et al. 2022c; Sekar et al. 2022).

Wang et al. investigated nano-titanium dioxide and activated carbon composite photocatalyst prepared by hydrothermal method using chlorine-free and low-cost inorganic peroxo-titanate to degrade methyl orange from wastewater. Titanium dioxide particles were dispersed well on the carbon surface, and no obvious aggregation was found. The composite catalyst titanium dioxide and activated carbon outperformed the titanium dioxide-activated carbon combination to remove methyl orange. (Wang et al. 2009). Matos et al. found a similar trend for removing 4-chlorophenol from wastewater, the possibility to use titanium dioxide-activated carbon as an alternative environmental green photocatalyst with high selectivity in organic synthesis (Matos et al. 2009).

\section{Photo-Fenton process}

$\mathrm{Fe}^{2+}$ or $\mathrm{Fe}^{3+}$ and $\mathrm{H}_{2} \mathrm{O}_{2}$ are sources of hydroxyl radicals in the photo-Fenton process. The Fenton reaction between $\mathrm{Fe}^{2+}$ and $\mathrm{H}_{2} \mathrm{O}_{2}$, which creates hydroxyl radical and causes $\mathrm{Fe}^{2+}$ to be oxidized to $\mathrm{Fe}^{+3}$, is at the heart of the chemistry (Brillas 2022; Rodrigues-Silva et al. 2022). The photo-Fenton process, which can use ultraviolet irradiation from natural solar light, often speeds up reaction rates and induces faster degradation of resistant pollutants than the dark process (Wang et al. 2021a; Ju et al. 2022).

$\mathrm{Fe}^{2+}$ ions are oxidized by $\mathrm{H}_{2} \mathrm{O}_{2}$ to $\mathrm{Fe}^{3+}$, and one corresponding hydroxyl radical is created in the photo-Fenton reaction (Park and Hur 2021; Rodríguez et al. 2021). The resulting $\mathrm{Fe}^{3+}$ acts as a light-absorbing species in aqueous solutions, producing additional radicals, while the $\mathrm{Fe}^{2+}$ is regenerated, as shown in the equations below.

$\mathrm{Fe}^{+2}+\mathrm{H}_{2} \mathrm{O}_{2} \rightarrow \mathrm{Fe}^{+3}+\cdot \mathrm{OH}+\mathrm{OH}^{-}$

$\mathrm{Fe}^{+3}+\mathrm{H}_{2} \mathrm{O}+h v \rightarrow \mathrm{Fe}^{+2}+\mathrm{OH}+\mathrm{H}^{+}$

The light sensitivity of the photo-Fenton process up to a wavelength of $600 \mathrm{~nm}$, which is 35 percent of solar irradiation, is its key benefit. Because a homogeneous solution is utilized, the light penetration depth is great, and the interaction between the contaminant and oxidizing catalyst is effective. The low $\mathrm{pH}$ values required, which are often below $\mathrm{pH}=4$, and the requirement of iron removal after the reaction are disadvantages; however, both issues could be avoided using a post-treatment procedure (Della-Flora et al. 2021; Wang et al. 2021b).

\section{Factors influencing the photo-Fenton process}

The Fenton reaction is among the most studied advanced oxidation processes in the last three decades, but its application in wastewater treatment just began in the 1990s. Hornstman, Henry John It was first described by Fenton, and it involves the formation of hydroxyl radicals in situ by the reaction of hydrogen peroxide with a ferrous salt (Çiner and Gökkuş 2013). The potent hydroxyl radical, which oxidizes organic molecules in a non-selective manner, can modify the chemical structure of pollutants in this physical-chemical process. With the right process conditions, total mineralization can be achieved, resulting in $\mathrm{CO}_{2}$, water, and organic acids (Kowalska et al. 2021; Maniakova et al. 2021; Ramalho et al. 2021).

Although the Fenton reaction has been known since the nineteenth century, it was only in 1968 that it was proposed as a wastewater treatment method. At first, atmospheric researchers investigated the photo-Fenton reaction to learn more about the natural mechanisms of hydrogen peroxide formation and the oxidation of numerous contaminants in atmospheric water droplets. It was then used to decompose wastewater containing various micro-pollutants, including pesticides, chlorophenols, natural phenolic pollutants, and medicines (Polo-López and Sánchez Pérez 2021; SorianoMolina et al. 2021b). It has also been used to treat wastewater with a high organic load of 10-20 g/L total organic carbon. Initially, contaminated wastewater has been shown to lose its toxicity after being treated with the photo-Fenton process before total mineralization. Toxicity is frequently followed by an increase in the biodegradability of treated wastewater (Fiorentino et al. 2021; Sanabria et al. 2021; Silva et al. 2021).

As a result, the photo-Fenton and advanced oxidation processes have been utilized as a pre-treatment to biological therapy in general (Soriano-Molina et al. 2021c, a). Several researchers have looked at the relationship between iron content, catalytic behavior, and temperature. Increases in the tested parameters, such as the maximum iron content of $2.6 \mathrm{mM}$ and the maximum temperature of $70{ }^{\circ} \mathrm{C}$, resulted in an increase in reaction rate (Cuervo Lumbaque et al. 2021; Guo et al. 2021; Rojas-Mantilla et al. 2021; Subramanian and Prakash 2021). Just one study looks at what happens when time intervals with and without illumination are alternated. It proposes the creation of precursors in the dark that are susceptible to fast photolysis when exposed to light.

In homogeneous Fenton reactions, iron species reside in the same phase as reactants. As a result, there is no restriction on mass transfer (Lai et al. 2021; Li and Cheng 2021). In numerous investigations, iron salts have been used successfully in the photo-Fenton method to treat a variety of resistant wastewaters (Casado et al. 2021; Yang et al. 2021a). Although homogeneous photo-Fenton has a high mineralization efficiency under ideal conditions, it has some drawbacks. The main disadvantage is developing a substantial amount of ferric-hydroxide sludge at $\mathrm{pH}$ values above 4.0, which negatively impacts the environment and waste 
management (Vilela et al. 2021; Xin et al. 2021). Furthermore, catalyst renewal is impractical, and a significant proportion of catalytic metal is lost in the sludge. The use of heterogeneous catalysts can help overcome some of these constraints (Rojas-Mantilla et al. 2021; Saber et al. 2021).

The most critical parameters that impact the efficacy of pollutant removal in the photo-Fenton oxidation process are the initial concentrations of the pollutant and Fenton reagents, acidity, and temperature of the mixture solution (Casado et al. 2021; Li and Cheng 2021; Nippes et al. 2021). In this case, optimizing the reaction is critical to achieving improved treatment outcomes. In numerous studies, multidimensional experimental design collected at one point methodology has been used instead of expensive and timeconsuming traditional procedures. To investigate the impacts of many experimental variables on the value of the selected response function, which is the proportion of chemical oxygen demand (COD) in percent or total organic carbon (TOC) in percent, removal (Xin et al. 2021).

\section{Effect of the concentration of contaminants}

One of the key elements in the photo-Fenton process is the concentration of pollutants. The inner filtering effect associated with high concentrations of absorbing molecules has been clearly demonstrated in literature research to have a negative impact on the removal efficiency of probe molecules as their concentration rises (Lin and Lin 2021; Brillas 2022). As a result, the reaction requires a longer irradiation period and/or more Fenton reagents to supply enough hydroxyl radicals. With initial concentrations of 60,100 , and $200 \mathrm{mg} / \mathrm{L}$, Feng and Le-Cheng, in 2004, examined the breakdown of phenol by photo-Fenton. It was discovered that raising the initial phenol concentration resulted in reduced degradation efficiency, measured as a percentage of the beginning concentration (Feng and Le-cheng 2004). Increasing the diclofenac content from 10 to $80 \mathrm{mg} / \mathrm{L}$ reduced the degradation efficiency and photo-Fenton reaction rate (Ravina et al. 2002). Ayodele et al. used a phosphoric acid modified kaolin clay supported ferric-oxalate catalyst to perform photo-Fenton for phenol degradation (Ayodele et al. 2012). Many researchers relate the decrease in degradation efficiency at higher concentrations to the consumption of Fenton chemicals before the degradation is finished (Subramanian and Prakash 2021; Vilela et al. 2021; Yang et al. 2021a).

\section{Effect of $\mathrm{pH}$}

The fundamental disadvantage of a homogeneous Fenton system is that it requires a high $\mathrm{pH}$ to achieve optimal degradation efficiency. This is not easy to solve, especially in natural waterways or wastewaters with strong buffering (Lin and Lin 2021). There is an agreement in the literature that the ideal $\mathrm{pH}$ range is 2.5-4.0 (Cabrera-Reina et al. 2021; Casado et al. 2021; Prada-Vásquez et al. 2021; Xin et al. 2021). The explanation for this is that species with a greater light absorption coefficient and quantum yield for hydroxyl radical production develop at $\mathrm{pH}$ levels approaching around 3.0, such as $\mathrm{Fe}(\mathrm{OH})_{2}{ }^{+}\left(\mathrm{H}_{2} \mathrm{O}\right)_{5}$, are produced (Rahim Pouran et al. 2014). After 360 min of photo-Fenton treatment at a pH of 6.2, Trovo' et al. found no change in amoxicillin (AMX) starting concentration. However, in the absence of light, the degradation efficacy at $\mathrm{pH} 2.5$ was 64 percent and 74 percent after 90 and 330 min, respectively. After 5.0 and 15 min, full amoxicillin elimination was achieved in this trial (Trovó et al. 2011). Luna et al. found that photo-Fenton breakdown of polyphenols at neutral and alkaline conditions under the influence of strong chlorine ions produced good results. The iron species in the solution are stabilized by $\mathrm{Fe}^{3+}$ complexation with chloride ions at $\mathrm{pH} 3$ (Luna et al. 2014).

Higher or lower $\mathrm{pH}$ values than optimal values have a negative impact on process performance. Due to the scavenging effect of $\mathrm{H}^{+}$ions and the generation of $\left[\mathrm{Fe}\left(\mathrm{H}_{2} \mathrm{O}\right)\right]^{2+}$ ion, which combines with $\mathrm{H}_{2} \mathrm{O}_{2}$ at a slower pace, lower $\mathrm{pH}$ produces a significant decrease in the number of hydroxyl radicals (Guo et al. 2021; Subramanian and Prakash 2021). Furthermore, a lower $\mathrm{pH}$ prevents $\mathrm{Fe}^{3+}$ and $\mathrm{H}_{2} \mathrm{O}_{2}$ from interacting. Another reason is that $\mathrm{H}_{2} \mathrm{O}_{2}$ is stable at $\mathrm{pH}$ below 3 due to the generation of $\mathrm{H}_{3} \mathrm{O}_{2}{ }^{+}$, which prevents the synthesis of hydroxyl radicals. (Li and Cheng 2021; Subramanian and Prakash 2021).

On the other hand, higher $\mathrm{pH}$ values interfere with Fenton effectiveness by preventing $\mathrm{H}_{2} \mathrm{O}_{2}$ breakdown from forming hydroxyl radicals due to a lack of $\mathrm{H}^{+}$ions. Furthermore, $\mathrm{H}_{2} \mathrm{O}_{2}$ decomposes into water and oxygen at a $\mathrm{pH}$ greater than 5.0. Additionally, rather than hydroxyl radicals, it is possible to generate more selective ferric species and develop ferric oxyhydroxide $(\mathrm{FeOOH})$, which slows the breakdown rate (Gar Alalm and Tawfik 2013). When the $\mathrm{pH}$ of a solution rises above 4, iron precipitates as ferric hydroxide, reducing light transmission and limiting photo-activity (Ballesteros Martín et al. 2009). Recent research on iron dosing strategies has shown that administering iron in multiple phases improves reaction rate at neutral $\mathrm{pH}$ values to the level achieved at pH 2.8 (Nippes et al. 2021; Soriano-Molina et al. 2021a).

\section{Fenton reagent dosage}

Fenton reagent dosage influences the reaction rate, degrading effectivity, and operating costs. One of the primary challenges in photo-Fenton is estimating the appropriate concentrations of reagents (Al-Balushi et al. 2021; Hernández-Coronado et al. 2021; Oller and Malato 2021). Due to 
the obvious importance of $\mathrm{H}_{2} \mathrm{O}_{2}$ concentration for determining quantitative oxidation and iron salt dose, both reagents must be present at their optimal concentrations. Because reactive oxidant species are not formed in the absence of $\mathrm{H}_{2} \mathrm{O}_{2}$, using solar light alone or with iron was ineffective (Rahim Pouran et al. 2014).

The kind and concentration of the contaminant have a big influence on the Fenton reagent dosage. As a result, depending on the results of the experiments, the ideal dosage is determined. Higher $\mathrm{H}_{2} \mathrm{O}_{2}$ dosages are required when the chemical oxygen demand (COD) is higher. On the other hand, optimal values are chosen to obtain higher deterioration at lower costs (Ahmad et al. 2019; Radwan et al. 2019). $\mathrm{H}_{2} \mathrm{O}_{2}$ did not influence the breakdown of agrochemical wastewater using photo-Fenton at low concentrations (10-50 $\mathrm{mmol} / \mathrm{L})$, while the effects clearly increased at larger concentrations of $\mathrm{H}_{2} \mathrm{O}_{2}$, such as $500 \mathrm{mmol} / \mathrm{L}$ (Nogueira et al. 2012). Many researchers discovered that increasing the amount of iron salt in the solution increased the rate of contaminant degradation until it reached the optimum dose, after which the rate of degradation decreased (MirallesCuevas et al. 2021; Oller and Malato 2021; Soriano-Molina et al. 2021c; Vilela et al. 2021).

Higher total dissolved solids (TDS), iron sludge development, scavenging of hydroxyl radicals, and a loss in color removal effectiveness due to possible interference of iron in color assessment are some of the difficulties associated with increasing iron concentration over the optimum dose (Rahim Pouran et al. 2014). Furthermore, at larger dosages above the optimum amount, the reaction rate reduced due to decreased ultraviolet-irradiation intensity produced by $\mathrm{Fe}$ $(\mathrm{OH})^{2+}$ formation in acidic media and its strong ultraviolet-light absorption impact (Rahim Pouran et al. 2014; Gar Alalm et al. 2015c).

\section{Types of photo-oxidation reactors}

Based on the deployed condition of the oxidants, photooxidation reactors for wastewater remediation may be categorized into two major designs. The first kind is the reactor with suspended catalyst particles or other oxidants. The second type is the reactor with photocatalyst immobilized onto continuous fixed support (Chong et al. 2010). Several types of photo-reactors were investigated in the literature. According to many researchers, the overall irradiation surface area of the catalyst per unit volume and light dispersion within the reactor are the most significant aspects in building a photocatalytic reactor (Soriano-Molina et al. 2021b; Wang et al. 2021a). The stationary structure is commonly related to mass transfer limitations through the photocatalyst immobilized layer, whereas the slurry-type reactors frequently reach a large total surface area of photocatalyst per given volume (Cabrera-Reina et al. 2021; Domenzain-Gonzalez et al. 2021; Lin et al. 2021; Peralta Muniz Moreira et al. 2021; Venier et al. 2021).

Mehrjouei et al. (Mehrjouei et al. 2013) studied a multiphase annular falling-film reactor for wastewater remediation using multi-oxidation methods, as shown in Fig. 5. The reactor comprises a borosilicate glass tube that is fixed coaxially inside another bigger tube from borosilicate glass using two aluminum caps surrounding the ultraviolet light source. Titanium dioxide particles were immobilized on the inner tube's outer surface and the outer tube's inner surface. Thus, the annular space between two tubes is used as a reaction medium. In this design, the wastewater is injected into the reactor through small apertures in the upper cap to form thin liquid falling films over the walls of tubes. The wastewater leaves the reactor from the bottom cap to be transferred into a storage container and then recycled again to the inlet point of the reactor. Two membrane pumps recycle the wastewater through the reactor over the inner and outer tubes separately.

Luna et al. (Luna et al. 2014) used a falling-film solar reactor (Fig. 6). It was made from a stainless-steel plate coupled with a $15-\mathrm{L}$ polypropylene mixing tank. A 4-mm thick borosilicate glass cover was placed on the plate surface to prevent evaporation of the reaction media during the tests. Borosilicate glass permits ultraviolet solar irradiation to reach the solution.

Similar to the falling film reactor, W-titanium dioxide was coated on tilted aluminum plates under simulated solar light for improving the reusability of the catalyst without the need for a tedious collecting process (Fouad et al. 2020). This design was further improved by including an additional chamber with a vertical coated plate to increase the irradiation time per water cycle showing high reusability of different photocatalysts (Samy et al. 2020b, c, e, 2021; Fouad et al. 2021c).

Many researchers used a parabolic collector reactor for solar photo-oxidation (Ahmed et al. 2011; Vilar et al. 2011; Fenoll et al. 2012). The reactor usually contains multiple borosilicate tubes but usually consist of Pyrex glass, placed atop polished aluminum reflectors that are curved. The water flows directly from the tube to the reservoir tank after being linked in series. This cycle is circulated many times in a closed circuit by a pump until the required irradiation time is achieved. The reaction system is usually continuously stirred to keep the solution's homogeneity and prevent the sedimentation of solids in the reactor or reservoir (Belalcázar-Saldarriaga et al. 2018; Esteban García et al. 2018; Cabrera-Reina et al. 2019). The configuration of a parabolic collector reactor is shown in Fig. 7.

An effective reactor design for photo-oxidation-based degradation of organic pollutants requires a high mass transfer rate, which is boosted by mixing the pollutants using turbulence and baffles. The liquid and gas flow rates control 
Fig. 5 Multi-phase annular falling-film reactor (Mehrjouei et al. 2013), the reactor system shows the ozone and solution inlets along with the immobilized titania particles, Titanium dioxide, UVA (ultraviolet-

A). The reactor comprises a borosilicate glass tube coaxially fixed inside a larger borosilicate glass tube by two aluminum caps surrounding the ultraviolet light source. Titanium dioxide particles were immobilized on the inner tube's outer surface and the outer tube's inner surface. The wastewater is pumped into the reactor through small holes in the upper cap to produce thin liquid dropping films on the walls of tubes, then exits the reactor through the bottom cap to be deposited into a storage container and recycled back to the reactor's inlet point. Two membrane pumps recycle the effluent independently through the reactor's inner and outer tubes

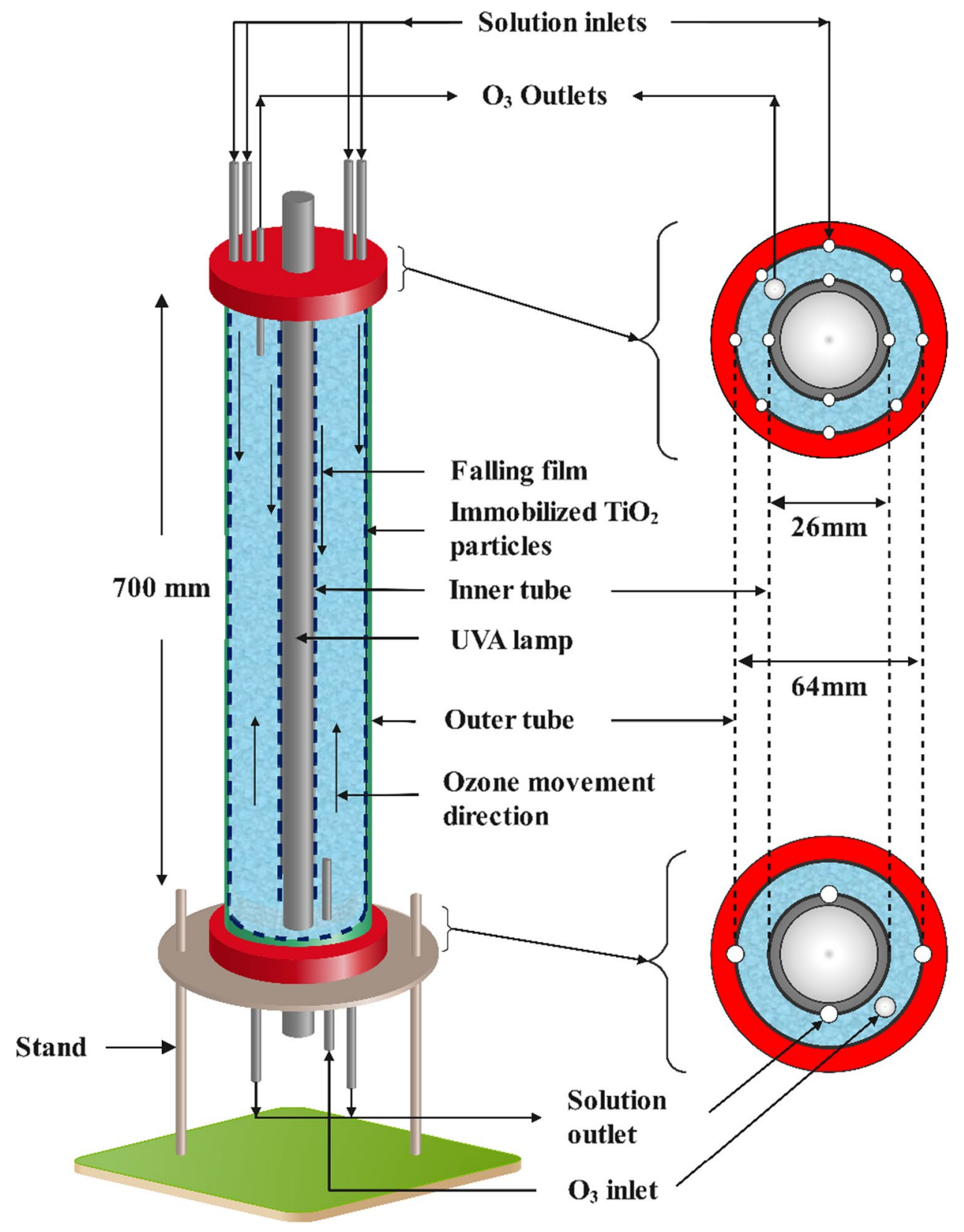

mass transfer in fixed-bed and fluidized-bed systems (Arzate et al. 2020; Talwar et al. 2020; Dai et al. 2021). Also, the penetration depth of light should be taken into consideration. Because both catalyst particles and contaminants absorb ultraviolet light, the penetration depth is restricted. Photocatalytic reactions take place on the semiconductor active sites, and the catalyst may be disseminated in the solution or immobilized on plates, but the catalyst must come into contact with the pollutant (de la Obra Jiménez et al. 2020; Mejri et al. 2020).

Furthermore, one of the most critical elements impacting the degradation rate is the oxygen content. The solubility at saturation conditions defines the oxygen content in water, which is thought to be largely constant (Dutta et al. 2019). However, to replenish the oxygen or air utilized in the oxidation process, oxygen or air is necessary. The total reaction rate could be slowed if dissolved oxygen levels are not replenished. Low oxygen solubility in water results in a low rate of oxygen reduction by controlled-band electrons, resulting in an electron buildup in a semiconductor. The pace of accumulation is accelerated due to this buildup (Fiorentino et al. 2019). Multi-channeled RPR-type solar collector effectively removed $94 \%$ and $78 \%$ of dyes and pesticides at a reaction time of $60 \mathrm{~min}$ (Dutta et al. 2019). Merino and Alonso (2019) successfully operated photo-Fenton solar process to remove $80 \%$ amoxicillin and paracetamol from 
Fig. 6 Solar falling film reactor (Luna et al. 2014). The reactor is composed of reaction volume, stirred tank, hydrogen peroxide vessel, peristaltic pump, centrifuge pump, sampling system along with regulator screw of the slope. The main parts of this system is a stainless-steel plate and a $15 \mathrm{~L}$ polypropylene mixing tank. To avoid evaporation of the reaction media during the testing, a 4-mm-thick borosilicate glass cover was installed on the plate surface. Ultraviolet sun irradiation can reach the solution via borosilicate glass

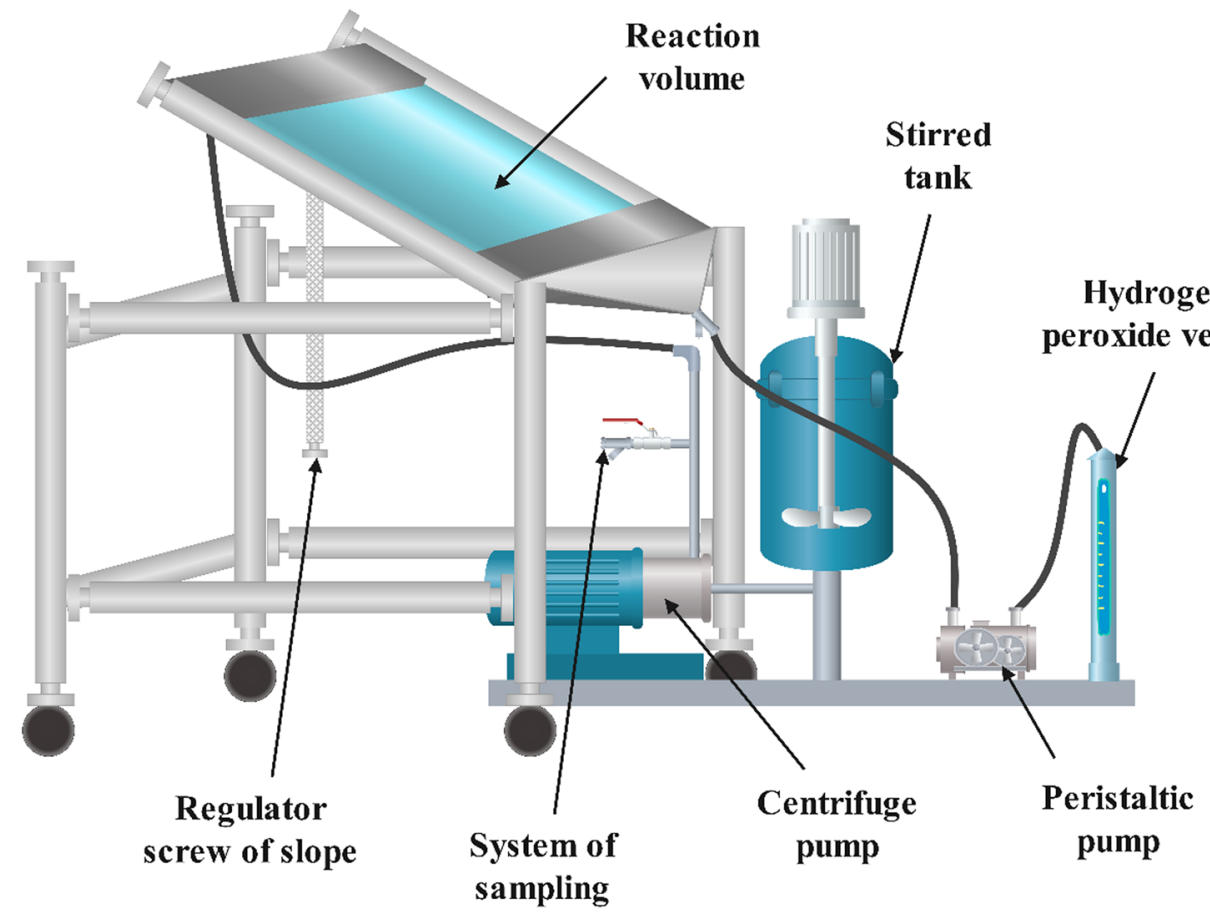

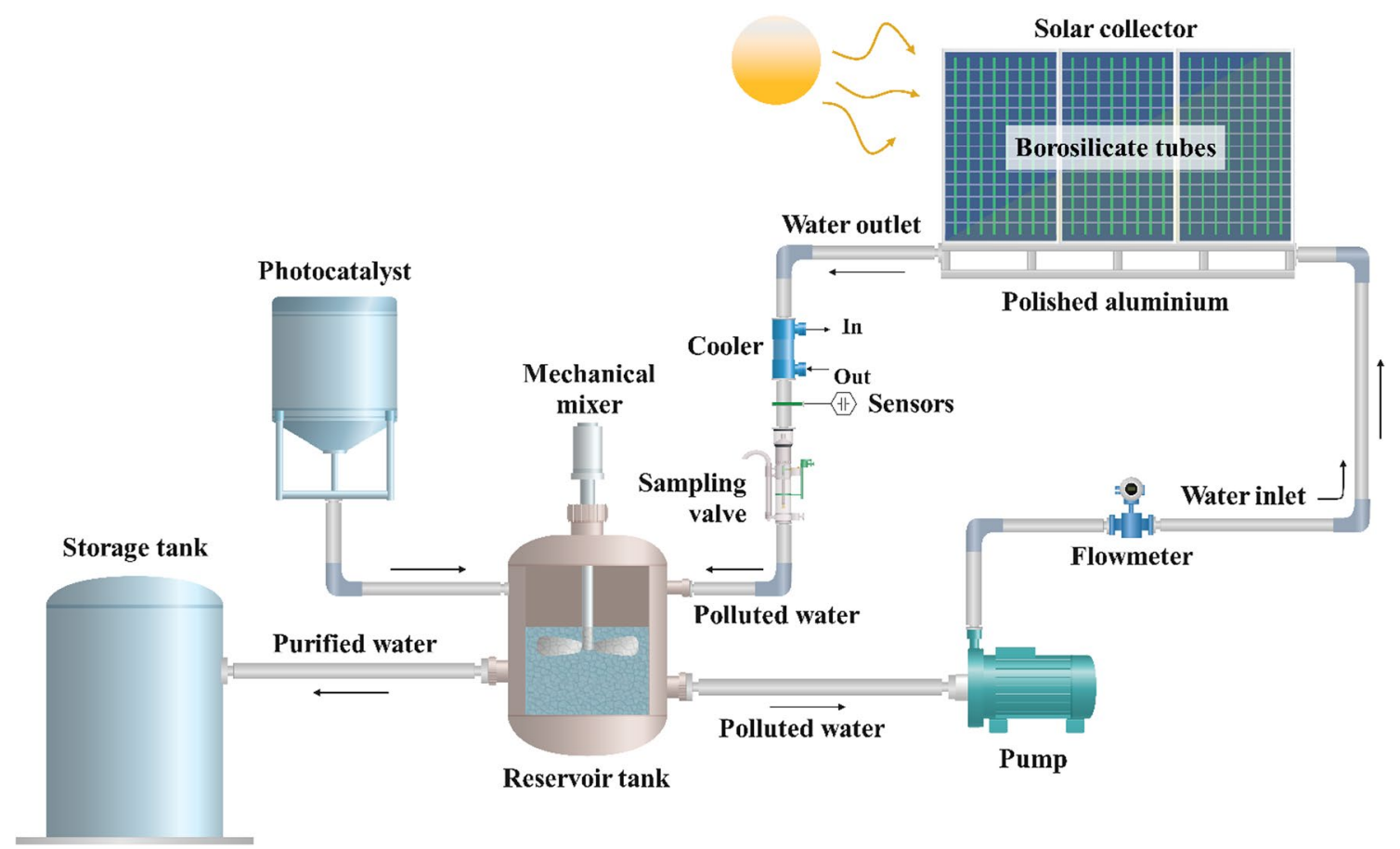

Fig. 7 A solar photo-oxidation parabolic collectors reactor (Fenoll et al. 2012), the reactor involves a solar collector, water flowmeter, sampling valve, mechanical mixer, reservoir tank, photocatalyst and a collector for the purified water. The reactor typically has numerous borosilicate tubes but is typically made of Pyrex glass and is positioned atop curved polished aluminum reflectors. After being coupled in series, the water flows directly from the tube to the reservoir tank. A pump circulates this cycle numerous times in a closed circuit until the requisite irradiation time is reached. The reaction system is often continually agitated to maintain solution homogeneity and to prevent particles from sedimenting in the reactor or reservoir 
the wastewater industry. Solar energy and electrochemical processes increased the oxidizing species resulting in a high degradation of the wastewater industry found that positive $\mathrm{P} / \mathrm{g}-\mathrm{C}_{3} \mathrm{~N}_{4}$ enhanced the thermo-coupled catalytic degradation of hazardous wastewater in the solar Vis-IR region (Oller et al. 2021) (Gu et al. 2020). Photo-oxidation processes are mainly dependent on ultraviolet light, so using ultraviolet transparent material for the solar reactor, such as borosilicate tubes, is recommended.

\section{Conclusion}

Among wastewater treatment processes, solar energy base processes are least implemented because of slow research and development in effective solar energy base reactors to degrade various contaminants. Conventional wastewater treatment processes are not very cost-effective, and process efficiencies are not up to the mark (Miralles-Cuevas et al. 2014)(Pancharoen et al. 2011). Photo-oxidation processes are mainly dependent on ultraviolet light, so using ultraviolet transparent material for the solar reactor such as borosilicate tubes is recommended. Various studies have discovered that the total irradiation surface area of catalyst per unit volume, as well as the dispersion of light within the reactor, is essential, which is the fixed-bed configuration's constraint. Moreover, the photo-Fenton process is advantageous as it has a light sensitivity up to $600 \mathrm{~nm}$, but the formation of a large quantity of the sludge has a huge effect on the environment and waste disposal issues. As for the limitations of the solar photocatalytic reactors could be the availability of a specific ultraviolet spectrum concerning the catalyst. At the same time, titanium dioxide with activated carbon could be a viable photocatalyst as activated carbon supports the photocatalytic activity of titanium dioxide. Titanium dioxide loaded on activated carbon has high selectivity in organic synthesis, which could also be used as an alternative environmental green photocatalyst.

Solar energy exposure is abundant in most of the world's regions, which is why this section of the research development needs to be recognized. Effectively designed solar photo-oxidation reactor systems are highly recommended, but it could be more efficient with pre-treatments and posttreatments for higher solar energy utilization to reduce electricity costs. Resultantly, it could provide us with high purity and recovery of reusable wastewater.

Furthermore, solar photo-oxidation reactors can be integrated with conventional wastewater treatments as pre or post-treatment reactors as an upgrade or addition to the already installed sequence. This review has shown plenty of improvement gaps in conventional and advanced oxidation processes for wastewater remediation.
Acknowledgements This research was funded by Science, Technology \& Innovation Funding Authority (STIFA), grant number " 26271 , 41591" and The Academy of scientific research and technology (ASRT) (Code: Call no. 2/2019/ASRT-Nexus) and Imhotep project partially financially supports the research. The $1^{\text {st }}$ author is grateful to the National Research Centre for partially supporting the research, grant number (12030202). This work was additionally supported by a grant from the Korea government's National Research Foundation (NRF) (MSIT) (2021R1A2C1092152) and the Ministry of Education's Priority Research Centers Program through the National Research Foundation of Korea (NRF) (2014R1A6A1031189). Dr Ahmed I. Osman wishes to acknowledge the support of The Bryden Centre project (Project ID VA5048), which was awarded by The European Union's INTERREG VA Programme, managed by the Special EU Programmes Body (SEUPB), with match funding provided by the Department for the Economy in Northern Ireland and the Department of Business, Enterprise and Innovation in the Republic of Ireland. The authors would also like to thank Charlie Farrell for proofreading the manuscript.

\section{Declarations}

Conflict of interest The authors declare no conflict of interest.

Disclaimer The views and opinions expressed in this review do not necessarily reflect those of the European Commission or the Special EU Programmes Body (SEUPB).

Open Access This article is licensed under a Creative Commons Attribution 4.0 International License, which permits use, sharing, adaptation, distribution and reproduction in any medium or format, as long as you give appropriate credit to the original author(s) and the source, provide a link to the Creative Commons licence, and indicate if changes were made. The images or other third party material in this article are included in the article's Creative Commons licence, unless indicated otherwise in a credit line to the material. If material is not included in the article's Creative Commons licence and your intended use is not permitted by statutory regulation or exceeds the permitted use, you will need to obtain permission directly from the copyright holder. To view a copy of this licence, visit http://creativecommons.org/licenses/by/4.0/.

\section{References}

Abidi M, Hajjaji A, Bouzaza A et al (2022) Modeling of indoor air treatment using an innovative photocatalytic luminous textile: reactor compactness and mass transfer enhancement. Chem Eng J 430:132636. https://doi.org/10.1016/j.cej.2021.132636

Adel A, Gar Alalm M, El-Etriby HK, Boffito DC (2020) Optimization and mechanism insights into the sulfamethazine degradation by bimetallic ZVI/Cu nanoparticles coupled with $\mathrm{H}_{2} \mathrm{O}_{2}$. J Environ Chem Eng. https://doi.org/10.1016/j.jece.2020.104341

Ahmad M, Chen S, Ye F et al (2019) Efficient photo-Fenton activity in mesoporous MIL-100(Fe) decorated with $\mathrm{ZnO}$ nanosphere for pollutants degradation. Appl Catal B Environ 245:428-438. https://doi.org/10.1016/j.apcatb.2018.12.057

Ahmadijokani F, Tajahmadi S, Rezakazemi M et al (2021) Aluminumbased metal-organic frameworks for adsorptive removal of anticancer (methotrexate) drug from aqueous solutions. J Environ Manage 277:111448. https://doi.org/10.1016/j.jenvman.2020. 111448

Ahmed MM, Chiron S (2014) Solar photo-Fenton like using persulphate for carbamazepine removal from domestic wastewater. 
Water Res 48:229-236. https://doi.org/10.1016/j.watres.2013. 09.033

Ahmed S, Rasul MG, Brown R, Hashib MA (2011) Influence of parameters on the heterogeneous photocatalytic degradation of pesticides and phenolic contaminants in wastewater: a short review. J Environ Manag 92:311-30. https://doi.org/10.1016/j.jenvman. 2010.08.028

Ahmed S, Rasul MG, Martens WN et al (2010) Heterogeneous photocatalytic degradation of phenols in wastewater: a review on current status and developments. Desalination 261:3-18. https:// doi.org/10.1016/j.desal.2010.04.062

Al-Balushi M, Lakkimsetty NR, Varghese MJ et al (2021) Evaluating the solar Photo-Fenton as photocatalyst process by response surface methodology to treat the saline water. Mater Today Proc. https://doi.org/10.1016/j.matpr.2021.07.024

Aliste M, Garrido I, Hernández V et al (2022) Assessment of reclaimed agro-wastewater polluted with insecticide residues for irrigation of growing lettuce (Lactuca sativa L) using solar photocatalytic technology. Environ Pollut 292:118367. https://doi.org/10.1016/j. envpol.2021.118367

Ambrosio E, Lucca DL, Garcia MHB et al (2017) Optimization of photocatalytic degradation of biodiesel using $\mathrm{TiO} 2 / \mathrm{H} 2 \mathrm{O} 2$ by experimental design. Sci Total Environ 581-582:1-9. https:// doi.org/10.1016/j.scitotenv.2016.11.177

Amiri H, Ayati B, Ganjidoust H (2016) Textile dye removal using photocatalytic cascade disk reactor coated by $\mathrm{ZnO}$ nanoparticles. J Mater Sci Chem Eng 04:29-38. https://doi.org/10.4236/msce. 2016.412004

Antonopoulou M, Kosma C, Albanis T, Konstantinou I (2021) An overview of homogeneous and heterogeneous photocatalysis applications for the removal of pharmaceutical compounds from real or synthetic hospital wastewaters under lab or pilot scale. Sci Total Environ 765:144163. https://doi.org/10.1016/j.scitotenv. 2020.144163

Arcanjo GS, Mounteer AH, Bellato CR et al (2018) Heterogeneous photocatalysis using $\mathrm{TiO} 2$ modified with hydrotalcite and iron oxide under UV-visible irradiation for color and toxicity reduction in secondary textile mill effluent. J Environ Manag 211:154163. https://doi.org/10.1016/j.jenvman.2018.01.033

Arzate S, Campos-Mañas MC, Miralles-Cuevas S et al (2020) Removal of contaminants of emerging concern by continuous flow solar photo-Fenton process at neutral $\mathrm{pH}$ in open reactors. J Environ Manage 261:110265. https://doi.org/10.1016/j.jenvman.2020. 110265

Assadi H, Armaghan F, Taheri RA (2021) Photocatalytic oxidation of ketone group volatile organic compounds in an intensified fluidized bed reactor using nano-TiO2/UV process: an experimental and modeling study. Chem Eng Process - Process Intensif 161:108312. https://doi.org/10.1016/j.cep.2021.108312

Ateia M, Gar Alalm M, Awfa D et al (2020) Modeling the degradation and disinfection of water pollutants by photocatalysts and composites: a critical review. Sci. Total Environ 698:134197

Atun G, Ortaboy S, Acar ET, Aydoğan SY (2022) Photocatalytic efficiency of titania nonylphenol ethoxylate composite thin films under solar irradiation. Mater Chem Phys 275:125210. https:// doi.org/10.1016/j.matchemphys.2021.125210

Ayodele OB, Lim JK, Hameed BH (2012) Degradation of phenol in photo-Fenton process by phosphoric acid modified kaolin supported ferric-oxalate catalyst: optimization and kinetic modeling. Chem Eng J 197:181-192. https://doi.org/10.1016/j.cej.2012.04. 053

Bai J, Shen R, Chen W et al (2022) Enhanced photocatalytic H2 evolution based on a $\mathrm{Ti}_{3} \mathrm{C}_{2} / \mathrm{Zn}_{0.7} \mathrm{Cd}_{0.3} \mathrm{~S} / \mathrm{Fe}_{2} \mathrm{O}_{3}$ Ohmic/S-scheme hybrid heterojunction with cascade 2D coupling interfaces. Chem Eng J 429:132587. https://doi.org/10.1016/j.cej.2021.132587
Ballesteros Martín MM, Sánchez Pérez JA, Casas López JL et al (2009) Degradation of a four-pesticide mixture by combined photo-Fenton and biological oxidation. Water Res 43:653-60. https://doi. org/10.1016/j.watres.2008.11.020

Bardestani R, Patience GS, Kaliaguine S (2019) Experimental methods in chemical engineering: specific surface area and pore size distribution measurements-BET, BJH, and DFT. Can J Chem Eng 97:2781-2791. https://doi.org/10.1002/cjce.23632

Bavykina A, Kolobov N, Khan IS et al (2020) Metal-organic frameworks in heterogeneous catalysis: recent progress, new trends, and future perspectives. Chem Rev 120:8468-8535. https://doi. org/10.1021/acs.chemrev.9b00685

Belalcázar-Saldarriaga A, Prato-Garcia D, Vasquez-Medrano R (2018) Photo-Fenton processes in raceway reactors: technical, economic, and environmental implications during treatment of colored wastewaters. J Clean Prod 182:818-829. https://doi. org/10.1016/j.jclepro.2018.02.058

Berkani M, Smaali A, Kadmi Y et al (2022) Photocatalytic degradation of Penicillin $\mathrm{G}$ in aqueous solutions: kinetic, degradation pathway, and microbioassays assessment. J Hazard Mater 421:126719. https://doi.org/10.1016/j.jhazmat.2021.126719

Brienza M, Mahdi Ahmed M, Escande A et al (2016) Use of solar advanced oxidation processes for wastewater treatment: Follow-up on degradation products, acute toxicity, genotoxicity and estrogenicity. Chemosphere 148:473-480. https://doi.org/ 10.1016/j.chemosphere.2016.01.070

Brillas E (2022) Fenton, photo-Fenton, electro-Fenton, and their combined treatments for the removal of insecticides from waters and soils. A review. Sep Purif Technol 284:120290. https://doi.org/10.1016/j.seppur.2021.120290

Bueno-Alejo CJ, Hueso JL, Mallada R et al (2019) High-radiance LED-driven fluidized bed photoreactor for the complete oxidation of n-hexane in air. Chem Eng J 358:1363-1370. https:// doi.org/10.1016/j.cej.2018.09.223

Cabrera-Reina A, Miralles-Cuevas S, Rivas G, Sánchez Pérez JA (2019) Comparison of different detoxification pilot plants for the treatment of industrial wastewater by solar photo-Fenton: Are raceway pond reactors a feasible option? Sci Total Environ 648:601-608. https://doi.org/10.1016/j.scitotenv.2018.08.143

Cabrera-Reina A, Miralles-Cuevas S, Sánchez Pérez JA, Salazar $\mathrm{R}$ (2021) Application of solar photo-Fenton in raceway pond reactors: a review. Sci Total Environ 800:149653. https://doi. org/10.1016/j.scitotenv.2021.149653

Carbajo J, Tolosana-Moranchel A, Casas JA et al (2018) Analysis of photoefficiency in $\mathrm{TiO} 2$ aqueous suspensions: Effect of titania hydrodynamic particle size and catalyst loading on their optical properties. Appl Catal B Environ 221:1-8. https://doi.org/10. 1016/j.apcatb.2017.08.032

Casado C, Moreno-SanSegundo J, De la Obra I et al (2021) Mechanistic modelling of wastewater disinfection by the photo-Fenton process at circumneutral $\mathrm{pH}$. Chem Eng J 403:126335. https://doi.org/10.1016/j.cej.2020.126335

Cerrato G, Bianchi CL, Galli F et al (2019) Micro-TiO2 coated glass surfaces safely abate drugs in surface water. J Hazard Mater 363:328-334. https://doi.org/10.1016/j.jhazmat.2018.09.057

Chatzimpaloglou A, Christophoridis C, Nika MC et al (2022) Degradation of antineoplastic drug etoposide in aqueous environment by photolysis and photocatalysis Identification of photocatalytic transformation products and toxicity assessment. Chem Eng J 431:133969. https://doi.org/10.1016/j.cej.2021.133969

Chaves RS, Guerreiro CS, Cardoso VV et al (2019) Hazard and mode of action of disinfection by-products (DBPs) in water for human consumption: Evidences and research priorities. Comp Biochem Physiol Part - C Toxicol Pharmacol 223:5361. https://doi.org/10.1016/j.cbpc.2019.05.015 
Chávez AM, Quiñones DH, Rey A et al (2020) Simulated solar photocatalytic ozonation of contaminants of emerging concern and effluent organic matter in secondary effluents by a reusable magnetic catalyst. Chem Eng J 398:125642. https://doi.org/ 10.1016/j.cej.2020.125642

Chen S, Hai G, Gao H et al (2021) Modulation of the charge transfer behavior of $\mathrm{Ni}(\mathrm{II})$-doped NH2-MIL-125(Ti): regulation of $\mathrm{Ni}$ ions content and enhanced photocatalytic $\mathrm{CO}_{2}$ reduction performance. Chem Eng J 406:126886. https://doi.org/10.1016/j. cej. 2020.126886

Chen X, Fang G, Liu C et al (2019) Cotransformation of carbon dots and contaminant under light in aqueous solutions: a mechanistic study. Environ Sci Technol 53:6235-6244. https://doi.org/ 10.1021/acs.est.8b07124

Chen Y, Wen L, Chen J et al (2022) In situ growth of g-C3N4 on clay minerals of kaolinite, sepiolite, and talc for enhanced solar photocatalytic energy conversion. Appl Clay Sci 216:106337. https:// doi.org/10.1016/j.clay.2021.106337

Chijioke-Okere MO, Adlan Mohd Hir Z, Ogukwe CE et al (2021) $\mathrm{TiO}_{2} /$ Polyethersulphone films for photocatalytic degradation of acetaminophen in aqueous solution. J Mol Liq 338:116692. https:// doi.org/10.1016/j.molliq.2021.116692

Chiou C-H, Juang R-S (2007) Photocatalytic degradation of phenol in aqueous solutions by Pr-doped TiO2 nanoparticles. J Hazard Mater 149:1-7. https://doi.org/10.1016/j.jhazmat.2007.03.035

Chong MN, Jin B, Chow CWK, Saint C (2010) Recent developments in photocatalytic water treatment technology: a review. Water Res 44:2997-3027. https://doi.org/10.1016/j.watres.2010.02.039

Çiner F, Gökkuş Ö (2013) Treatability of dye solutions containing disperse dyes by Fenton and Fenton-solar light oxidation processes. CLEAN - Soil, Air, Water 41:80-85. https://doi.org/10. 1002/clen.201000500

Cuervo Lumbaque E, Cardoso RM, de Araújo GA et al (2021) Removal of pharmaceuticals in hospital wastewater by solar photo-Fenton with Fe3+-EDDS using a pilot raceway pond reactor: transformation products and in silico toxicity assessment. Microchem $\mathrm{J}$ 164:106014. https://doi.org/10.1016/j.microc.2021.106014

Dai T, Li C, Wang N et al (2021) Efficient degradation of azo dye by dual-doped photo-enhanced Fenton-like catalysts in magnetic suspension reactor. J Ind Eng Chem 104:390-396. https://doi. org/10.1016/j.jiec.2021.08.031

Daneshvar N, Aber S, Seyeddorraji M et al (2007) Photocatalytic degradation of the insecticide diazinon in the presence of prepared nanocrystalline $\mathrm{ZnO}$ powders under irradiation of UV-C light. Sep Purif Technol 58:91-98. https://doi.org/10.1016/j.seppur. 2007.07.016

de la Obra JI, Giannakis S, Grandjean D et al (2020) Unfolding the action mode of light and homogeneous vs. heterogeneous photoFenton in bacteria disinfection and concurrent elimination of micropollutants in urban wastewater, mediated by iron oxides in Raceway Pond Reactors. Appl Catal B Environ 263:118158. https://doi.org/10.1016/j.apcatb.2019.118158

Dehkordi AB, Badiei A (2022) Insight into the activity of TiO2@ nitrogen-doped hollow carbon spheres supported on g-C3N4 for robust photocatalytic performance. Chemosphere 288:132392. https://doi.org/10.1016/j.chemosphere.2021.132392

Della-Flora A, Wilde ML, Lima D et al (2021) Combination of tertiary solar photo-Fenton and adsorption processes in the treatment of hospital wastewater: the removal of pharmaceuticals and their transformation products. J Environ Chem Eng 9:105666. https:// doi.org/10.1016/j.jece.2021.105666

Deng M, Wu X, Zhu A et al (2019) Well-dispersed TiO 2 nanoparticles anchored on $\mathrm{Fe}_{3} \mathrm{O}_{4}$ magnetic nanosheets for efficient arsenic removal. J Environ Manag 237:63-74. https://doi.org/10.1016/j. jenvman.2019.02.037
Doll TE, Frimmel FH (2004) Kinetic study of photocatalytic degradation of carbamazepine, clofibric acid, iomeprol and iopromide assisted by different $\mathrm{TiO} 2$ materials-determination of intermediates and reaction pathways. Water Res 38:955-964. https://doi. org/10.1016/j.watres.2003.11.009

Domenzain-Gonzalez J, Castro-Arellano JJ, Galicia-Luna LA et al (2021) Photocatalytic membrane reactor based on Mexican Natural Zeolite: RB5 dye removal by photo-Fenton process. J Environ Chem Eng 9:105281. https://doi.org/10.1016/j.jece.2021.105281

Dong Z, Zondag SDA, Schmid M et al (2022) A meso-scale ultrasonic milli-reactor enables gas-liquid-solid photocatalytic reactions in flow. Chem Eng J 428:130968. https://doi.org/10.1016/j.cej. 2021.130968

Dutta A, Das N, Sarkar D, Chakrabarti S (2019) Development and characterization of a continuous solar-collector-reactor for wastewater treatment by photo-Fenton process. Sol Energy 177:364373. https://doi.org/10.1016/j.solener.2018.11.036

Eke R, Betts TR, Gottschalg R (2017) Spectral irradiance effects on the outdoor performance of photovoltaic modules. Renew Sustain Energy Rev 69:429-434. https://doi.org/10.1016/j.rser.2016.10. 062

Elmolla ES, Chaudhuri M (2010) Degradation of amoxicillin, ampicillin and cloxacillin antibiotics in aqueous solution by the UV/ZnO photocatalytic process. J Hazard Mater 173:445-449. https://doi. org/10.1016/j.jhazmat.2009.08.104

Enríquez R, Pichat P (2006) Different net effect of TiO2 sintering temperature on the photocatalytic removal rates of 4-chlorophenol, 4-chlorobenzoic acid and dichloroacetic acid in water. J Environ Sci Health A Tox Hazard Subst Environ Eng 41:955-966. https:// doi.org/10.1080/10934520600689233

Esteban García B, Rivas G, Arzate S, Sánchez Pérez JA (2018) Wild bacteria inactivation in WWTP secondary effluents by solar photo-fenton at neutral $\mathrm{pH}$ in raceway pond reactors. Catal Today 313:72-78. https://doi.org/10.1016/j.cattod.2017.10.031

Fang T, Yang C, Liao L (2012) Photoelectrocatalytic degradation of high COD dipterex pesticide by using $\mathrm{TiO} 2 / \mathrm{Ni}$ photo electrode. J Environ Sci 24:1149-1156. https://doi.org/10.1016/S10010742(11)60882-6

Fathinia M, Khataee A, Vahid B, Joo SW (2020) Scrutinizing the vital role of various ultraviolet irradiations on the comparative photocatalytic ozonation of albendazole and metronidazole: integration and synergistic reactions mechanism. J Environ Manag 272:111044. https://doi.org/10.1016/j.jenvman.2020.111044

Fatima R, Kim JO (2021) Inhibiting photocatalytic electron-hole recombination by coupling MIL-125(Ti) with chemically reduced, nitrogen-containing graphene oxide. Appl Surf Sci 541:148503. https://doi.org/10.1016/j.apsusc.2020.148503

Feng HE, Le-cheng LEI (2004) Degradation kinetics and mechanisms of phenol in photo-Fenton process. J Zhejiang Univ Sci 5:198-205

Fenoll J, Flores P, Hellín P et al (2012) Photodegradation of eight miscellaneous pesticides in drinking water after treatment with semiconductor materials under sunlight at pilot plant scale. Chem Eng J 204-206:54-64. https://doi.org/10.1016/j.cej.2012.07.077

Fiorentino A, Esteban B, Garrido-Cardenas JA et al (2019) Effect of solar photo-Fenton process in raceway pond reactors at neutral $\mathrm{pH}$ on antibiotic resistance determinants in secondary treated urban wastewater. J Hazard Mater 378:120737. https://doi.org/ 10.1016/j.jhazmat.2019.06.014

Fiorentino A, Prete P, Rizzo L et al (2021) Fe3+- IDS as a new green catalyst for water treatment by photo-Fenton process at neutral pH. J Environ Chem Eng 9:106802. https://doi.org/10.1016/j. jece.2021.106802

Fouad K, Bassyouni M, Alalm MG, Saleh MY (2021a) Recent developments in recalcitrant organic pollutants degradation using 
immobilized photocatalysts. Appl Phys A 127:612. https://doi. org/10.1007/s00339-021-04724-1

Fouad K, Bassyouni M, Alalm MG, Saleh MY (2021) The treatment of wastewater containing pharmaceuticals. J Environ Treat Tech 9:499-504. https://doi.org/10.47277/JETT/9(2)504

Fouad K, Gar Alalm M, Bassyouni M, Saleh MY (2020) A novel photocatalytic reactor for the extended reuse of $\mathrm{W}_{-} \mathrm{TiO}_{2}$ in the degradation of sulfamethazine. Chemosphere 257:127270. https:// doi.org/10.1016/j.chemosphere.2020.127270

Fouad M, Gar Alalm M, El-Etriby HK et al (2021c) Visible-lightdriven photocatalytic disinfection of raw surface waters (300$5000 \mathrm{CFU} / \mathrm{mL}$ ) using reusable coated $\mathrm{Ru} / \mathrm{WO} / \mathrm{ZrO} 2$. J Hazard Mater 402:123514. https://doi.org/10.1016/j.jhazmat.2020. 123514

Fujiwara K, Yano A (2011) Controllable spectrum artificial sunlight source system using LEDs with 32 different peak wavelengths of 385-910nm. Bioelectromagnetics 32:243-252. https://doi.org/ 10.1002/bem.20637

Gar Alalm M, Djellabi R, Meroni D et al (2021) Toward scaling-up photocatalytic process for multiphase environmental applications. Catalysts 11:562. https://doi.org/10.3390/catal11050562

Gar Alalm M, Nasr M (2018) Artificial intelligence, regression model, and cost estimation for removal of chlorothalonil pesticide by activated carbon prepared from casuarina charcoal. Sustain Environ Res 28:101-110. https://doi.org/10.1016/j.serj.2018.01.003

Gar Alalm M, Samy M, Ookawara S, Ohno T (2018) Immobilization of S-TiO2 on reusable aluminum plates by polysiloxane for photocatalytic degradation of 2,4-dichlorophenol in water. J Water Process Eng 26:329-335. https://doi.org/10.1016/j.jwpe.2018. 11.001

Gar Alalm M, Tawfik A, Ookawara S (2015a) Combined Solar advanced oxidation and PAC adsorption for removal of pesticides from industrial wastewater. J Mater Environ Sci 6:800-809

Gar Alalm M, Tawfik A, Ookawara S (2014) Solar photocatalytic degradation of phenol by $\mathrm{TiO}_{2} / \mathrm{AC}$ prepared by temperature impregnation method. Desalin Water Treat. https://doi.org/10. 1080/19443994.2014.969319

Gar Alalm M, Tawfik A, Ookawara S (2016) Enhancement of photocatalytic activity of $\mathrm{TiO} 2$ by immobilization on activated carbon for degradation of pharmaceuticals. J Environ Chem Eng 4:1929-1937. https://doi.org/10.1016/j.jece.2016.03.023

Gar Alalm M, Tawfik A, Ookawara S (2015b) Comparison of solar $\mathrm{TiO} 2$ photocatalysis and solar photo-Fenton for treatment of pesticides industry wastewater : operational conditions, kinetics, and costs. J Water Process Eng 8:55-63. https://doi.org/10.1016/j. jwpe.2015.09.007

Gar Alalm M, Tawfik A, Ookawara S (2015c) Degradation of four pharmaceuticals by solar photo-Fenton process: kinetics and costs estimation. J Environ Chem Eng 3:46-51. https://doi.org/ 10.1016/j.jece.2014.12.009

Garcia-Muñoz P, Fresno F, Ivanez J et al (2020a) Activity enhancement pathways in LaFeO3@TiO2 heterojunction photocatalysts for visible and solar light driven degradation of myclobutanil pesticide in water. J Hazard Mater 400:123099. https://doi.org/ 10.1016/j.jhazmat.2020.123099

Garcia-Muñoz P, Fresno F, Lefevre C et al (2020b) Highly robust La1xTixFeO3 dual catalyst with combined photocatalytic and photoCWPO activity under visible light for 4-chlorophenol removal in water. Appl Catal B Environ 262:118310. https://doi.org/10. 1016/j.apcatb.2019.118310

Gernjak W (2006) Solar photo-Fenton treatment of EU priority substances process parameters and control strategies. Dr Thesis

Giannakis S, Lin KYA, Ghanbari F (2021) A review of the recent advances on the treatment of industrial wastewaters by Sulfate Radical-based Advanced Oxidation Processes (SR-AOPs). Chem Eng J 406:127083. https://doi.org/10.1016/j.cej.2020.127083
Gora SL, Andrews SA (2019) Removal of natural organic matter and disinfection byproduct precursors from drinking water using photocatalytically regenerable nanoscale adsorbents. Chemosphere 218:52-63. https://doi.org/10.1016/j.chemosphere.2018.11.102

Gu D, Zhang S, Jiang T et al (2020) Positive P / g-C 3 N 4 thermo-coupled photocatalytic oxidation of refractory organics in wastewater for total utilization of solar Vis-IR region. Mater Chem Phys. https://doi.org/10.1016/j.matchemphys.2020.123307

Guo Q, Zhu W, Yang D et al (2021) A green solar photo-Fenton process for the degradation of carbamazepine using natural pyrite and organic acid with in-situ generated $\mathrm{H} 2 \mathrm{O} 2$. Sci Total Environ 784:147187. https://doi.org/10.1016/j.scitotenv.2021.147187

Hameed BH, Salman JM, Ahmad AL (2009) Adsorption isotherm and kinetic modeling of 2,4-D pesticide on activated carbon derived from date stones. J Hazard Mater 163:121-6. https://doi.org/10. 1016/j.jhazmat.2008.06.069

Harijan DKL, Gupta S, Ben SK et al (2022) High photocatalytic efficiency of $\alpha-\mathrm{Fe} 2 \mathrm{O} 3$ - ZnO composite using solar energy for methylene blue degradation. Phys B Condens Matter 627:413567. https://doi.org/10.1016/j.physb.2021.413567

Heidari Z, Alizadeh R, Ebadi A et al (2020) Degradation of furosemide using photocatalytic ozonation in the presence of $\mathrm{ZnO} /$ ICLT nanocomposite particles: experimental, modeling, optimization and mechanism evaluation. J Mol Liq 319:114193. https://doi.org/10.1016/j.molliq.2020.114193

Hernández-Coronado EE, Ruiz-Ruiz EJ, Hinojosa-Reyes L et al (2021) Effective degradation of cefuroxime by heterogeneous photo-Fenton under simulated solar radiation using $\alpha-\mathrm{Fe} 2 \mathrm{O} 3-$ TiO2. J Environ Chem Eng 9:106822. https://doi.org/10. 1016/j.jece.2021.106822

Hinojosa-Reyes M, Arriaga S, Diaz-Torres LA, Rodríguez-González V (2013) Gas-phase photocatalytic decomposition of ethylbenzene over perlite granules coated with indium doped $\mathrm{TiO} 2$. Chem Eng J 224:106-113. https://doi.org/10.1016/j.cej.2013. 01.066

Hu K, Zhang M, Liu B et al (2021) Efficient electrochemical oxidation of 5-hydroxymethylfurfural to 2,5-furandicarboxylic acid using the facilely synthesized 3D porous WO3/Ni electrode. Mol Catal 504:111459. https://doi.org/10.1016/j.mcat.2021.111459

Huang C, Wang J, Li M et al (2021) Construction of a novel Z-scheme V2O5/NH2-MIL-101(Fe) composite photocatalyst with enhanced photocatalytic degradation of tetracycline. Solid State Sci 117:106611. https://doi.org/10.1016/j.solidstatesciences. 2021.106611

Huang J, Xue P, Wang S et al (2022) Fabrication of zirconium-based metal-organic frameworks@tungsten trioxide (UiO-66-NH2@ WO3) heterostructure on carbon cloth for efficient photocatalytic removal of tetracycline antibiotic under visible light. J Colloid Interface Sci 606:1509-1523. https://doi.org/10.1016/j.jcis.2021. 08.108

Janin T, Goetz V, Brosillon S, Plantard G (2013) Solar photocatalytic mineralization of 2,4-dichlorophenol and mixtures of pesticides: kinetic model of mineralization. Sol Energy 87:127-135. https:// doi.org/10.1016/j.solener.2012.10.017

Jin Z, Li J, Liu D et al (2022) Effective promotion of spacial charge separation of dual S-scheme (1D/2D/0D) WO3@ZnIn2S4/Bi2S3 heterojunctions for enhanced photocatalytic performance under visible light. Sep Purif Technol 284:120207. https://doi.org/10. 1016/j.seppur.2021.120207

Ju Y, Li H, Wang Z et al (2022) Solar-driven on-site H2O2 generation and tandem photo-Fenton reaction on a triphase interface for rapid organic pollutant degradation. Chem Eng J 430:133168. https://doi.org/10.1016/j.cej.2021.133168

Kaneco S, Rahman MA, Suzuki T et al (2004) Optimization of solar photocatalytic degradation conditions of bisphenol A in 
water using titanium dioxide. J Photochem Photobiol A Chem 163:419-424. https://doi.org/10.1016/j.jphotochem.2004.01.012

Kartal O, Erol M, Oguz H (2001) Photocatalytic destruction of phenol by TiO 2 powders. Chem Eng Technol 24:645-649

Khan H, Usen N, Boffito DC (2019) Spray-dried microporous Pt/TiO2 degrades 4-chlorophenol under UV and visible light. J Environ Chem Eng 7:103267. https://doi.org/10.1016/j.jece.2019.103267

Kim B, Jang J, Lee DS (2022) Enhanced photocatalytic degradation of bisphenol A by magnetically separable bismuth oxyiodide magnetite nanocomposites under solar light irradiation. Chemosphere 289:133040. https://doi.org/10.1016/j.chemosphere.2021.133040

Klamerth N, Miranda N, Malato S et al (2009) Degradation of emerging contaminants at low concentrations in MWTPs effluents with mild solar photo-Fenton and TiO2. Catal Today 144:124-130. https://doi.org/10.1016/j.cattod.2009.01.024

Kovacic M, Papac J, Kusic H et al (2019) Degradation of polar and non-polar pharmaceutical pollutants in water by solar assisted photocatalysis using hydrothermal $\mathrm{TiO} 2-\mathrm{SnS} 2$. Chem Eng J 382:122826. https://doi.org/10.1016/j.cej.2019.122826

Kowalska K, Roccamante M, Cabrera Reina A et al (2021) Pilot-scale removal of microcontaminants by solar-driven photo-Fenton in treated municipal effluents: selection of operating variables based on lab-scale experiments. J Environ Chem Eng 9:104788. https:// doi.org/10.1016/j.jece.2020.104788

Kumar A, Khan M, He J, Lo IMC (2020) Recent developments and challenges in practical application of visible-light-driven $\mathrm{TiO} 2-$ based heterojunctions for PPCP degradation: a critical review. Water Res 170:115356. https://doi.org/10.1016/j.watres.2019. 115356

Lai W, Chen Z, Ye S et al (2021) BiVO4 prepared by the sol-gel doped on graphite felt cathode for ciprofloxacin degradation and mechanism in solar-photo-electro-Fenton. J Hazard Mater 408:124621. https://doi.org/10.1016/j.jhazmat.2020.124621

Lam S-M, Sin J-C, Mohamed AR (2010) Parameter effect on photocatalytic degradation of phenol using TiO2-P25/activated carbon (AC). Korean J Chem Eng 27:1109-1116. https://doi.org/ 10.1007/s11814-010-0169-8

Lathasree S, Rao AN, Sivasankar B et al (2004) Heterogeneous photocatalytic mineralisation of phenols in aqueous solutions. J Mol Catal A Chem 223:101-105. https://doi.org/10.1016/j.molcata. 2003.08.032

Latif A, Memon AM, Gadhi TA et al (2022) Bi2O3 immobilized 3D structured clay filters for solar photocatalytic treatment of wastewater from batch to scaleup reactors. Mater Chem Phys 276:125297. https://doi.org/10.1016/j.matchemphys. 2021. 125297

Lebedev VA, Kozlov DA, Kolesnik IV et al (2016) The amorphous phase in titania and its influence on photocatalytic properties. Appl Catal B Environ 195:39-47. https://doi.org/10.1016/j. apcatb.2016.05.010

Lewis AJ, Joyce T, Hadaya M et al (2020) Rapid degradation of PFAS in aqueous solutions by reverse vortex flow gliding arc plasma. Environ Sci Water Res Technol 6:1044-1057. https://doi.org/10. 1039/c9ew01050e

Li D, Liu Y, Yang Y et al (2022) Rational construction of Ag3PO4/ WO3 step-scheme heterojunction for enhanced solar-driven photocatalytic performance of $\mathrm{O} 2$ evolution and pollutant degradation. J Colloid Interface Sci 608:2549-2559. https://doi.org/10. 1016/j.jcis.2021.10.178

Li K, Jiang Y, Rao W et al (2022) Cooperative coupling strategy for constructing $0 \mathrm{D} / 2 \mathrm{D}$ carbon nitride composites with strengthened chemical interaction for enhanced photocatalytic applications. Chem Eng J 431:134075. https://doi.org/10.1016/j.cej.2021. 134075

Li K, Sun C, Chen Z et al (2022) Fe-carbon dots enhance the photocatalytic nitrogen fixation activity of TiO2@ $\mathrm{CN}$ heterojunction.
Chem Eng J 429:132440. https://doi.org/10.1016/j.cej.2021. 132440

Li Puma G, Yue PL (2002) Effect of the radiation wavelength on the rate of photocatalytic oxidation of organic pollutants. Ind Eng Chem Res 41:5594-5600. https://doi.org/10.1021/ie0203274

Li W, Wang Z, Li Y et al (2022) Visible-NIR light-responsive 0D/2D CQDs/Sb2WO6 nanosheets with enhanced photocatalytic degradation performance of RhB: unveiling the dual roles of CQDs and mechanism study. J Hazard Mater 424:127595. https://doi. org/10.1016/j.jhazmat.2021.127595

Li Y, Cheng H (2021) Chemical kinetic modeling of organic pollutant degradation in Fenton and solar photo-Fenton processes. J Taiwan Inst Chem Eng 123:175-184. https://doi.org/10.1016/j. jtice.2021.05.011

Liang Y, Wu X, Liu X et al (2022) Recovering solar fuels from photocatalytic $\mathrm{CO} 2$ reduction over $\mathrm{W} 6+$-incorporated crystalline g-C3N4 nanorods by synergetic modulation of active centers. Appl Catal B Environ 304:120978. https://doi.org/10.1016/j. apcatb.2021.120978

Lima MJ, Silva AMT, Silva CG et al (2022) Selective photocatalytic synthesis of benzaldehyde in microcapillaries with immobilized carbon nitride. Chem Eng J 430:132643. https://doi.org/ 10.1016/j.cej.2021.132643

Lin HH-H, Lin AY-C (2021) Solar photo-Fenton oxidation of cytostatic drugs via $\mathrm{Fe}(\mathrm{III})$-EDDS at circumneutral $\mathrm{pH}$ in an aqueous environment. J Water Process Eng 41:102066. https://doi. org/10.1016/j.jwpe.2021.102066

Lin Y-T, Wang Y-H, Wu JCS, Wang X (2021) Photo-Fenton enhanced twin-reactor for simultaneously hydrogen separation and organic wastewater degradation. Appl Catal B Environ 281:119517. https://doi.org/10.1016/j.apcatb.2020.119517

Ling Y, Alzate-Sánchez DM, Klemes MJ et al (2020) Evaluating the effects of water matrix constituents on micropollutant removal by activated carbon and $\beta$-cyclodextrin polymer adsorbents. Water Res. https://doi.org/10.1016/j.watres.2020.115551

Lopez-Alvarez B, Torres-Palma RA, Peñuela G (2011) Solar photocatalitycal treatment of carbofuran at lab and pilot scale: effect of classical parameters, evaluation of the toxicity and analysis of organic by-products. J Hazard Mater 191:196-203. https:// doi.org/10.1016/j.jhazmat.2011.04.060

Lu M, Zhang H (2022) Preparation and decontamination performance of a flexible self-standing hydrogel photocatalytic membrane. J Memb Sci 644:119979. https://doi.org/10.1016/j. memsci.2021.119979

Luna AJ, Nascimento CAO, Foletto EL et al (2014) Photo-Fenton degradation of phenol, 2,4-dichlorophenoxyacetic acid and 2,4-dichlorophenol mixture in saline solution using a fallingfilm solar reactor. Environ Technol 35:364-371. https://doi. org/10.1080/09593330.2013.828762

M Gar Alalm, A Tawfik A (2013) Fenton and solar photo-Fenton oxidation of industrial wastewater containing pesticides. 17th Int water Technol Conf 2:5-7

Mafa PJ, Malefane ME, Idris AO et al (2022) Multi-elemental doped g-C3N4 with enhanced visible light photocatalytic activity: insight into naproxen degradation, kinetics, effect of electrolytes, and mechanism. Sep Purif Technol 282:120089. https:// doi.org/10.1016/j.seppur.2021.120089

Magdy M, Gar Alalm M, El-Etriby HK (2021) Comparative life cycle assessment of five chemical methods for removal of phenol and its transformation products. J Clean Prod 291:125923. https://doi.org/10.1016/j.jclepro.2021.125923

Maniakova G, Salmerón I, Aliste M et al (2021) Solar photo-Fenton at circumneutral $\mathrm{pH}$ using $\mathrm{Fe}(\mathrm{III})$-EDDS compared to ozonation for tertiary treatment of urban wastewater: contaminants of emerging concern removal and toxicity assessment. Chem Eng J. https://doi.org/10.1016/j.cej.2021.133474 
Marinho BA, Djellabi R, Cristóvão RO et al (2017) Intensification of heterogeneous $\mathrm{TiO} 2$ photocatalysis using an innovative micromeso-structured-reactor for $\mathrm{Cr}(\mathrm{VI})$ reduction under simulated solar light. Chem Eng J 318:76-88. https://doi.org/10.1016/j. cej.2016.05.077

Martín-Sómer M, Pablos C, de Diego A et al (2019) Novel macroporous 3D photocatalytic foams for simultaneous wastewater disinfection and removal of contaminants of emerging concern. Chem Eng J 366:449-459. https://doi.org/10.1016/j.cej.2019. 02.102

Martínez-Pachón D, Serna-Galvis EA, Ibañez M et al (2021) Treatment of two sartan antihypertensives in water by photo-electro-Fenton using BDD anodes: degradation kinetics, theoretical analyses, primary transformations and matrix effects. Chemosphere 270:129491. https://doi.org/10.1016/j.chemosphere.2020.129491

Matiazzo T, Ramaswamy K, Vilar VJP et al (2022) Radiation field modeling of the NETmix milli-photocatalytic reactor: effect of LEDs position over the reactor window. Chem Eng J 429:131670. https://doi.org/10.1016/j.cej.2021.131670

Matos J, Garcia A, Cordero T et al (2009) Eco-friendly TiO2-AC photocatalyst for the selective photooxidation of 4-chlorophenol. Catal Lett 130:568-574. https://doi.org/10.1007/ s10562-009-9989-8

Mehrjouei M, Müller S, Möller D (2013) Design and characterization of a multi-phase annular falling-film reactor for water treatment using advanced oxidation processes. J Environ Manag 120:6874. https://doi.org/10.1016/j.jenvman.2013.02.021

Mejri A, Soriano-Molina P, Miralles-Cuevas S, Sánchez Pérez JA (2020) Fe3+-NTA as iron source for solar photo-Fenton at neutral $\mathrm{pH}$ in raceway pond reactors. Sci Total Environ 736:139617. https://doi.org/10.1016/j.scitotenv.2020.139617

Merino AA, Alonso JMQ (2019) Oxidation mechanisms of amoxicillin and paracetamol in the photo-Fenton solar process. Water Res 156:232-240. https://doi.org/10.1016/j.watres.2019.02.055

Miralles-Cuevas S, Oller I, Ruiz AA et al (2014) Removal of pharmaceuticals at microg $\mathrm{L}-1$ by combined nanofiltration and mild solar photo-Fenton. Chem Eng J 239:68-74. https://doi.org/10. 1016/j.cej.2013.10.047

Miralles-Cuevas S, Soriano-Molina P, de la Obra I et al (2021) Simultaneous bacterial inactivation and microcontaminant removal by solar photo-Fenton mediated by Fe3+-NTA in WWTP secondary effluents. Water Res 205:117686. https://doi.org/10.1016/j. watres.2021.117686

Mohanta D, Ahmaruzzaman M (2021) Facile fabrication of novel $\mathrm{Fe} 3 \mathrm{O} 4-\mathrm{SnO} 2-\mathrm{gC} 3 \mathrm{~N} 4$ ternary nanocomposites and their photocatalytic properties towards the degradation of carbofuran. Chemosphere. https://doi.org/10.1016/j.chemosphere.2021.131395

Monteagudo JM, Durán A, Martínez MR, San Martín I (2020) Effect of reduced graphene oxide load into $\mathrm{TiO} 2 \mathrm{P} 25$ on the generation of reactive oxygen species in a solar photocatalytic reactor. Application to antipyrine degradation. Chem Eng J 380:122410. https://doi.org/10.1016/j.cej.2019.122410

Nashat M, Mossad M, El-Etriby HK, Gar Alalm M (2022) Optimization of electrochemical activation of persulfate by BDD electrodes for rapid removal of sulfamethazine. Chemosphere 286:131579. https://doi.org/10.1016/j.chemosphere.2021.131579

Nippes RP, Macruz PD, Neves Olsen Scaliante MH (2021) Toxicity reduction of persistent pollutants through the photo-fenton process and radiation/ $\mathrm{H} 2 \mathrm{O} 2$ using different sources of radiation and neutral pH. J Environ Manag 289:112500. https://doi.org/10. 1016/j.jenvman.2021.112500

Nogueira KRB, Nascimento CAO, Guardani R, Teixeira ACSC (2012) Feasibility study of a solar reactor for phenol treatment by the photo-fenton process in aqueous solution. Chem Eng Technol 35:2125-2132. https://doi.org/10.1002/ceat.201200269
Oller I, Malato S (2021) Photo-Fenton applied to the removal of pharmaceutical and other pollutants of emerging concern. Curr Opin Green Sustain Chem 29:100458. https://doi.org/10.1016/j.cogsc. 2021.100458

Oller I, Malato S, Salmer I (2021) Chemosphere Solar photo-assisted electrochemical processes applied to actual industrial and urban wastewaters : a practical approach based on recent literature. Chemosphere. https://doi.org/10.1016/j.chemosphere.2021. 130560

Pan J, Wang L, Shi Y et al (2022) Construction of nanodiamonds/ UiO-66-NH2 heterojunction for boosted visible-light photocatalytic degradation of antibiotics. Sep Purif Technol 284:120270. https://doi.org/10.1016/j.seppur.2021.120270

Pancharoen U, Leepipatpiboon N, Ramakul P (2011) Innovative approach to enhance uranium ion flux by consecutive extraction via hollow fiber supported liquid membrane. J Ind Eng Chem 17:647-650. https://doi.org/10.1016/j.jiec.2011.05.016

Parida KM, Parija S (2006) Photocatalytic degradation of phenol under solar radiation using microwave irradiated zinc oxide. Sol Energy 80:1048-1054. https://doi.org/10.1016/j.solener.2005.04.025

Park E, Hur J (2021) Three-dimensionally interconnected porous PDMS decorated with poly(dopamine) and Prussian blue for floatable, flexible, and recyclable photo-Fenton catalyst activated by solar light. Appl Surf Sci 545:148990. https://doi.org/ 10.1016/j.apsusc.2021.148990

Parrino F, Corsino SF, Bellardita M et al (2019) Sequential biological and photocatalysis based treatments for shipboard slop purification: a pilot plant investigation. Process Saf Environ Prot 125:288-296. https://doi.org/10.1016/j.psep.2019.03.025

Pattappan D, Kavya KV, Vargheese S et al (2022) Graphitic carbon nitride/NH2-MIL-101(Fe) composite for environmental remediation: Visible-light-assisted photocatalytic degradation of acetaminophen and reduction of hexavalent chromium. Chemosphere 286:131875. https://doi.org/10.1016/j.chemosphere.2021.131875

Peralta Muniz Moreira R, Cabrera Reina A, Soriano Molina P et al (2021) Computational fluid dynamics (CFD) modeling of removal of contaminants of emerging concern in solar photoFenton raceway pond reactors. Chem Eng J 413:127392. https:// doi.org/10.1016/j.cej.2020.127392

Phanikrishna Sharma MV, Sadanandam G, Ratnamala A et al (2009) An efficient and novel porous nanosilica supported $\mathrm{TiO} 2$ photocatalyst for pesticide degradation using solar light. J Hazard Mater 171:626-633. https://doi.org/10.1016/j.jhazmat.2009.06. 040

Polo-López MI, Sánchez Pérez JA (2021) Perspectives of the solar photo-Fenton process against the spreading of pathogens, antibiotic-resistant bacteria and genes in the environment. Curr Opin Green Sustain Chem 27:100416. https://doi.org/10.1016/j.cogsc. 2020.100416

Prada-Vásquez MA, Estrada-Flórez SE, Serna-Galvis EA, TorresPalma RA (2021) Developments in the intensification of photoFenton and ozonation-based processes for the removal of contaminants of emerging concern in Ibero-American countries. Sci Total Environ 765:142699. https://doi.org/10.1016/j.scito tenv.2020.142699

Priya MH, Madras G (2006) Photocatalytic degradation of nitrobenzenes with combustion synthesized nano-TiO2. J Photochem Photobiol A Chem 178:1-7. https://doi.org/10.1016/j.jphot ochem.2005.06.012

Qin Y, Xue C, Yu H et al (2021) The construction of bio-inspired hierarchically porous graphene aerogel for efficiently organic pollutants absorption. J Hazard Mater 419:126441. https://doi.org/ 10.1016/j.jhazmat.2021.126441

Radwan M, Gar Alalm M, El-Etriby HK (2019) Application of electro-Fenton process for treatment of water contaminated with 
benzene, toluene, and p-xylene (BTX) using affordable electrodes. J Water Process Eng 31:100837. https://doi.org/10.1016/j. jwpe.2019.100837

Radwan M, Gar Alalm M, Eletriby H (2018) Optimization and modeling of electro-Fenton process for treatment of phenolic wastewater using nickel and sacrificial stainless steel anodes. J Water Process Eng 22:155-162. https://doi.org/10.1016/j.jwpe.2018. 02.003

Rafaely RX, Sabatini CA, Zaiat M, Azevedo EB (2021) Perfluorooctane sulfonic acid (PFOS) degradation by optimized heterogeneous photocatalysis (TiO2/UV) using the response surface methodology (RSM). J Water Process Eng 41:101986. https://doi.org/ 10.1016/j.jwpe.2021.101986

Rahim Pouran S, Abdul Aziz AR, Wan Daud WMA (2014) Review on the main advances in photo-Fenton oxidation system for recalcitrant wastewaters. J Ind Eng Chem. https://doi.org/10.1016/j. jiec.2014.05.005

Ramalho MLA, Madeira VS, Brasileiro ILO et al (2021) Synthesis of mixed oxide $\mathrm{Ti} / \mathrm{Fe} 2 \mathrm{O} 3$ as solar light-induced photocatalyst for heterogeneous photo-Fenton like process. J Photochem Photobiol A Chem 404:112873. https://doi.org/10.1016/j.jphotochem.2020. 112873

Ramalingam G, Pachaiappan R, Kumar PS et al (2022) Hybrid metal organic frameworks as an Exotic material for the photocatalytic degradation of pollutants present in wastewater: a review. Chemosphere 288:132448. https://doi.org/10.1016/j.chemosphere. 2021.132448

Ravina M, Campanella L, Kiwi J (2002) Accelerated mineralization of the drug Diclofenac via Fenton reactions in a concentric photoreactor. Water Res 36:3553-3560

Rayati S, Zamanifard A, Nejabat F, Hoseini S (2021) Photocatalytic potential of an immobilized free-base porphyrin for the oxidation of organic substrates. Mol Catal 516:111950. https://doi.org/10. 1016/j.mcat.2021.111950

Ren X, Liu F, Wang Q et al (2022) Engineering interfacial charge transfer channel for efficient photocatalytic $\mathrm{H} 2$ evolution: the interplay of CoPx and Ca2+ dopant. Appl Catal B Environ 303:120887. https://doi.org/10.1016/j.apcatb.2021.120887

Rodrigues-Silva F, Lemos CR, Naico AA et al (2022) Study of isoniazid degradation by Fenton and photo-Fenton processes, byproducts analysis and toxicity evaluation. J Photochem Photobiol A Chem 425:113671. https://doi.org/10.1016/j.jphotochem.2021. 113671

Rodríguez M, Bussi J, Andrea De León M (2021) Application of pillared raw clay-base catalysts and natural solar radiation for water decontamination by the photo-Fenton process. Sep Purif Technol 259:118167. https://doi.org/10.1016/j.seppur.2020.118167

Rojas-Mantilla HD, Ayala-Duran SC, Pupo Nogueira RF (2021) Nontronite mineral clay NAu-2 as support for hematite applied as catalyst for heterogeneous photo-Fenton processes. Chemosphere 277:130258. https://doi.org/10.1016/j.chemosphere.2021.130258

Rueda-Marquez JJ, Levchuk I, Fernández Ibañez P, Sillanpää M (2020) A critical review on application of photocatalysis for toxicity reduction of real wastewaters. J Clean Prod. https://doi.org/10. 1016/j.jclepro.2020.120694

Saber AN, Djellabi R, Fellah I et al (2021) Synergistic sorption/photoFenton removal of typical substituted and parent polycyclic aromatic hydrocarbons from coking wastewater over $\mathrm{CuO}$-Montmorillonite. J Water Process Eng 44:102377. https://doi.org/10. 1016/j.jwpe.2021.102377

Saien J, Khezrianjoo S (2008) Degradation of the fungicide carbendazim in aqueous solutions with UV/TiO2 process: optimization, kinetics and toxicity studies. J Hazard Mater 157:269-276. https://doi.org/10.1016/j.jhazmat.2007.12.094
Samy M, Gar Alalm M, Fujii M, Ibrahim MG (2021) Journal of water process engineering doping of Ni in MIL-125 ( $\mathrm{Ti}$ ) for enhanced photocatalytic degradation of carbofuran : reusability of coated plates and effect of different water matrices. J Water Process Eng 44:102449. https://doi.org/10.1016/j.jwpe.2021.102449

Samy M, Ibrahim MG, Alalm MG, Fujii M (2020) Modeling and optimization of photocatalytic degradation of methylene blue using lanthanum vanadate. Mater Sci Forum 1008:97-103

Samy M, Ibrahim MG, Gar Alalm M et al (2020b) Photocatalytic degradation of trimethoprim using $\mathrm{S}-\mathrm{TiO} 2$ and $\mathrm{Ru} / \mathrm{WO} 3 / \mathrm{ZrO} 2$ immobilized on reusable fixed plates. J Water Process Eng 33:310. https://doi.org/10.1016/j.jwpe.2019.101023

Samy M, Ibrahim MG, Gar Alalm M et al (2020c) Innovative photocatalytic reactor for the degradation of chlorpyrifos using a coated composite of $\mathrm{ZrV} 2 \mathrm{O} 7$ and graphene nano-platelets. Chem Eng J 395:124974. https://doi.org/10.1016/j.cej.2020.124974

Samy M, Ibrahim MG, Gar Alalm M, Fujii M (2020d) Effective photocatalytic degradation of sulfamethazine by CNTs / LaVO 4 in suspension and dip coating modes. Sep Purif Technol 235:35516. https://doi.org/10.1016/j.seppur.2019.116138

Samy M, Ibrahim MG, Gar Alalm M, Fujii M (2020e) MIL-53(Al)/ $\mathrm{ZnO}$ coated plates with high photocatalytic activity for extended degradation of trimethoprim via novel photocatalytic reactor. Sep Purif Technol 249:117173. https://doi.org/10.1016/j.seppur.2020. 117173

Sanabria P, Scunderlick D, Wilde ML et al (2021) Solar photo-Fenton treatment of the anti-cancer drug anastrozole in different aqueous matrices at near-neutral $\mathrm{pH}$ : transformation products identification, pathways proposal, and in silico (Q)SAR risk assessment. Sci Total Environ 754:142300. https://doi.org/10.1016/j.scito tenv. 2020.142300

Sekar S, Preethi V, Saravanan S et al (2022) Excellent photocatalytic performances of $\mathrm{Co} 3 \mathrm{O} 4-\mathrm{AC}$ nanocomposites for $\mathrm{H} 2$ production via wastewater splitting. Chemosphere 286:131823. https://doi. org/10.1016/j.chemosphere.2021.131823

Serrà A, Philippe L, Perreault F, Garcia-Segura S (2021) Photocatalytic treatment of natural waters reality or hype? the case of cyanotoxins remediation. Water Res. https://doi.org/10.1016/j.watres. 2020.116543

Shah NS, Iqbal J, Sayed M et al (2022) Enhanced solar light photocatalytic performance of $\mathrm{Fe}-\mathrm{ZnO}$ in the presence of $\mathrm{H} 2 \mathrm{O} 2$, S2O82-, and HSO5- for degradation of chlorpyrifos from agricultural wastes: toxicities investigation. Chemosphere 287:132331. https://doi.org/10.1016/j.chemosphere.2021.132331

Sharma P, Shahi VK (2020) Assembly of MIL-101(Cr)-sulphonated poly(ether sulfone) membrane matrix for selective electrodialytic separation of $\mathrm{Pb} 2+$ from mono-/bi-valent ions. Chem Eng J 382:122688. https://doi.org/10.1016/j.cej.2019.122688

Silva M, Baltrus J, Williams C et al (2021) Mesoporous Fe-doped MgO nanoparticles as a heterogeneous photo-Fenton-like catalyst for degradation of salicylic acid in wastewater. J Environ Chem Eng 9:105589. https://doi.org/10.1016/j.jece.2021.105589

Singh HK, Saquib M, Haque MM, Muneer M (2007) Heterogeneous photocatalysed degradation of 4-chlorophenoxyacetic acid in aqueous suspensions. J Hazard Mater 142:374-380. https://doi. org/10.1016/j.jhazmat.2006.08.032

Soriano-Molina P, De la Obra I, Miralles-Cuevas S et al (2021) Assessment of different iron sources for continuous flow solar photoFenton at neutral $\mathrm{pH}$ for sulfamethoxazole removal in actual MWWTP effluents. J Water Process Eng 42:102109. https://doi. org/10.1016/j.jwpe.2021.102109

Soriano-Molina P, Miralles-Cuevas S, Esteban García B et al (2021) Two strategies of solar photo-Fenton at neutral $\mathrm{pH}$ for the simultaneous disinfection and removal of contaminants of emerging concern. Comparative assessment in raceway pond reactors. 
Catal Today 361:17-23. https://doi.org/10.1016/j.cattod.2019. 11.028

Soriano-Molina P, Miralles-Cuevas S, Oller I et al (2021) Contribution of temperature and photon absorption on solar photo-Fenton mediated by $\mathrm{Fe} 3+-\mathrm{NTA}$ for CEC removal in municipal wastewater. Appl Catal B Environ 294:120251. https://doi.org/10.1016/j. apcatb.2021.120251

Su S, Xing Z, Zhang S et al (2021) Ultrathin mesoporous g-C3N4/ NH2-MIL-101(Fe) octahedron heterojunctions as efficient photoFenton-like system for enhanced photo-thermal effect and promoted visible-light-driven photocatalytic performance. Appl Surf Sci 537:147890. https://doi.org/10.1016/j.apsusc.2020.147890

Subramanian G, Prakash H (2021) Photo augmented copper-based fenton disinfection under visible LED light and natural sunlight irradiation. Water Res 190:116719. https://doi.org/10.1016/j. watres.2020.116719

Sühnholz S, Gawel A, Kopinke FD, Mackenzie K (2021) Evidence of heterogeneous degradation of PFOA by activated persulfate $\mathrm{FeS}$ as adsorber and activator. Chem Eng J 423:130102. https:// doi.org/10.1016/j.cej.2021.130102

Sun G, Shi J-W, Mao S et al (2022) Dodecylamine coordinated triarm CdS nanorod wrapped in intermittent $\mathrm{ZnS}$ shell for greatly improved photocatalytic H2 evolution. Chem Eng J 429:132382. https://doi.org/10.1016/j.cej.2021.132382

Talwar S, Verma AK, Sangal VK (2020) Plug flow approaching novel reactor employing in-situ dual effect of photocatalysis and photo-Fenton for the degradation of metronidazole. Chem Eng $\mathbf{J}$ 382:122772. https://doi.org/10.1016/j.cej.2019.122772

Tang R, Gong D, Deng Y et al (2022) $\pi-\pi$ Stacked step-scheme PDI/gC3N4/TiO2@Ti3C2 photocatalyst with enhanced visible photocatalytic degradation towards atrazine via peroxymonosulfate activation. Chem Eng J 427:131809. https://doi.org/10.1016/j. cej.2021.131809

Tawfik M, Tonnellier X, Sansom C (2018) Light source selection for a solar simulator for thermal applications: a review. Renew Sustain Energy Rev 90:802-813. https://doi.org/10.1016/j.rser.2018.03. 059

Teoh SK, Li LY (2020) Feasibility of alternative sewage sludge treatment methods from a lifecycle assessment (LCA) perspective. J Clean Prod 247:119495. https://doi.org/10.1016/j.jclepro.2019. 119495

Tolba A, Gar Alalm M, Elsamadony M et al (2019) Modeling and optimization of heterogeneous Fenton-like and photo-Fenton processes using reusable Fe3O4-MWCNTs. Process Saf Environ Prot 128:273-283. https://doi.org/10.1016/j.psep.2019.06.011

Trovó AG, Nogueira RFP, Agüera A et al (2011) Degradation of the antibiotic amoxicillin by photo-Fenton process-chemical and toxicological assessment. Water Res 45:1394-1402. https://doi. org/10.1016/j.watres.2010.10.029

Valadez-Renteria E, Oliva J, Rodriguez-Gonzalez V (2022) Photocatalytic materials immobilized on recycled supports and their role in the degradation of water contaminants: a timely review. Sci Total Environ 807:150820. https://doi.org/10.1016/j.scitotenv. 2021.150820

Venier CM, Conte LO, Pérez-Moya M et al (2021) A CFD study of an annular pilot plant reactor for Paracetamol photo-Fenton degradation. Chem Eng J 410:128246. https://doi.org/10.1016/j.cej. 2020.128246

Vilar VJP, Pinho LX, Pintor AMA, Boaventura RAR (2011) Treatment of textile wastewaters by solar-driven advanced oxidation processes. Sol Energy 85:1927-1934. https://doi.org/10.1016/j. solener.2011.04.033

Vilela PB, Mendonça Neto RP, Starling MCVM et al (2021) Metagenomic analysis of MWWTP effluent treated via solar photo-Fenton at neutral $\mathrm{pH}$ : Effects upon microbial community, priority pathogens, and antibiotic resistance genes. Sci Total Environ 801:149599. https://doi.org/10.1016/j.scitotenv.2021.149599

Vu NN, Kaliaguine S, Do TO (2020) Plasmonic photocatalysts for sunlight-driven reduction of CO2: details, developments, and perspectives. Chemsuschem 13:3967-3991. https://doi.org/10. 1002/cssc.202000905

Wang B, Yan C, Xu G et al (2022) Highly efficient solar-driven photocatalytic hydrogen evolution with FeMoSx/mpg-C3N4 heterostructure. Chem Eng J 427:131507. https://doi.org/10.1016/j.cej. 2021.131507

Wang L, Ma X, Huang G et al (2022b) Construction of ternary CuO / $\mathrm{CuFe} 2 \mathrm{O} 4$ / g-C $3 \mathrm{~N} 4$ composite and its enhanced photocatalytic degradation of tetracycline hydrochloride with persulfate under simulated sunlight. J Environ Sci 112:59-70. https://doi. org/10.1016/j.jes.2021.04.026

Wang L, Tang G, Liu S et al (2022) Interfacial active-site-rich 0D Co3O4/1D TiO2 p-n heterojunction for enhanced photocatalytic hydrogen evolution. Chem Eng J 428:131338. https://doi.org/10. 1016/j.cej.2021.131338

Wang Q, Wang P, Xu P et al (2021) Submerged membrane photocatalytic reactor for advanced treatment of p-nitrophenol wastewater through visible-light-driven photo-Fenton reactions. Sep Purif Technol 256:117783. https://doi.org/10.1016/j.seppur.2020. 117783

Wang W, Liu Y, Yu S et al (2022) Highly efficient solar-light-driven photocatalytic degradation of pollutants in petroleum refinery wastewater on hierarchically-structured copper sulfide (CuS) hollow nanocatalysts. Sep Purif Technol 284:120254. https://doi. org/10.1016/j.seppur.2021.120254

Wang X, Li Z, Zhang Y et al (2022) Enhanced photocatalytic antibacterial and degradation performance by p-n-p type CoFe2O4/ $\mathrm{CoFe} 2 \mathrm{~S} 4 / \mathrm{MgBi} 2 \mathrm{O} 6$ photocatalyst under visible light irradiation. Chem Eng J 429:132270. https://doi.org/10.1016/j.cej.2021. 132270

Wang X, Liu Y, Hu Z et al (2009) Degradation of methyl orange by composite photocatalysts nano-TiO2 immobilized on activated carbons of different porosities. J Hazard Mater 169:1061-1067. https://doi.org/10.1016/j.jhazmat.2009.04.058

Wang Y-Y, Chen Y-X, Barakat T et al (2022) Recent advances in nonmetal doped titania for solar-driven photocatalytic/photoelectrochemical water-splitting. J Energy Chem 66:529-559. https://doi. org/10.1016/j.jechem.2021.08.038

Wang Y, Zhao M, Hou C et al (2021) Efficient degradation of perfluorooctanoic acid by solar photo-electro-Fenton like system fabricated by MOFs/carbon nanofibers composite membrane. Chem Eng J 414:128940. https://doi.org/10.1016/j.cej.2021.128940

Wei L, Shifu C, Wei Z, Sujuan Z (2009) Titanium dioxide mediated photocatalytic degradation of methamidophos in aqueous phase. J Hazard Mater 164:154-160. https://doi.org/10.1016/j.jhazmat. 2008.07.140

Wu W, Zhu S, Huang X et al (2021) Mechanisms of persulfate activation on biochar derived from two different sludges: dominance of their intrinsic compositions. J Hazard Mater 408:124454. https:// doi.org/10.1016/j.jhazmat.2020.124454

Wu Y, Hu Y, Han M et al (2021b) Mechanism insights into the facetdependent photocatalytic degradation of perfluorooctanoic acid on BiOCl nanosheets. Chem Eng J 425:130672. https://doi.org/ 10.1016/j.cej.2021.130672

Xie Z, Xu W, Fang F et al (2022) Gel-assisted synthesis of CIZS for visible-light photocatalytic reduction reaction. Chem Eng J 429:132364. https://doi.org/10.1016/j.cej.2021.132364

Xin S, Ma B, Liu G et al (2021) Enhanced heterogeneous photo-Fenton-like degradation of tetracycline over $\mathrm{CuFeO} 2 /$ biochar catalyst through accelerating electron transfer under visible light. J Environ Manage 285:112093. https://doi.org/10.1016/j.jenvm an.2021.112093 
Xiong M, Qin Y, Chai B et al (2022) Unveiling the role of Mn-Cd-S solid solution and $\mathrm{MnS}$ in MnxCd1-xS photocatalysts and decorating with $\mathrm{CoP}$ nanoplates for enhanced photocatalytic $\mathrm{H} 2$ evolution. Chem Eng J 428:131069. https://doi.org/10.1016/j.cej. 2021.131069

Xu X, Su Y, Dong Y et al (2022) Designing and fabricating a CdS QDs/Bi2MoO6 monolayer S-scheme heterojunction for highly efficient photocatalytic $\mathrm{C} 2 \mathrm{H} 4$ degradation under visible light. J Hazard Mater 424:127685. https://doi.org/10.1016/j.jhazmat. 2021.127685

Yang J, Luo X (2021) Ag-doped TiO2 immobilized cellulose-derived carbon beads: One-Pot preparation, photocatalytic degradation performance and mechanism of ceftriaxone sodium. Appl Surf Sci 542:148724. https://doi.org/10.1016/j.apsusc.2020.148724

Yang L, Xiang Y, Jia F et al (2021) Photo-thermal synergy for boosting photo-Fenton activity with rGO-ZnFe2O4: Novel photo-activation process and mechanism toward environment remediation. Appl Catal B Environ 292:120198. https://doi.org/10.1016/j. apcatb.2021.120198

Yang W, Tang S, Wei Z et al (2021b) Separate-free BiPO4/graphene aerogel with $3 \mathrm{D}$ network structure for efficient photocatalytic mineralization by adsorption enrichment and photocatalytic degradation. Chem Eng J 421:129720. https://doi.org/10.1016/j.cej. 2021.129720

Yang Y, Ji W, Li X et al (2021c) Insights into the degradation mechanism of perfluorooctanoic acid under visible-light irradiation through fabricating flower-shaped $\mathrm{Bi} 5 \mathrm{O} 7 \mathrm{I} / \mathrm{ZnO}$ n-n heterojunction microspheres. Chem Eng J 420:129934. https://doi.org/10. 1016/j.cej.2021.129934

Yao C, Zhang Y, Du M et al (2019) Insights into the mechanism of nonradical activation of persulfate via activated carbon for the degradation of p-chloroaniline. Chem Eng J 362:262-268. https:// doi.org/10.1016/j.cej.2019.01.040

Yuan Y, Feng L, He X et al (2022) Efficient removal of PFOA with an In2O3/persulfate system under solar light via the combined process of surface radicals and photogenerated holes. J Hazard Mater 423:127176. https://doi.org/10.1016/j.jhazmat.2021. 127176

Yue X, Cheng L, Fan J, Xiang Q (2022) 2D/2D BiVO4/CsPbBr 3 $\mathrm{S}$-scheme heterojunction for photocatalytic $\mathrm{CO} 2$ reduction: insights into structure regulation and Fermi level modulation. Appl Catal B Environ 304:120979. https://doi.org/10.1016/j. apcatb.2021.120979

Zaitsev AV, Astapov IA (2022) Prospects for creating regenerated photocatalytic materials for solar water treatment units. Mater Lett 310:131509. https://doi.org/10.1016/j.matlet.2021.131509

Zapata A, Oller I, Sirtori C et al (2010) Decontamination of industrial wastewater containing pesticides by combining large-scale homogeneous solar photocatalysis and biological treatment. Chem Eng J 160:447-456. https://doi.org/10.1016/j.cej.2010. 03.042
Zeng G, You H, Du M et al (2021) Enhancement of photocatalytic activity of TiO2 by immobilization on activated carbon for degradation of aquatic naphthalene under sunlight irradiation. Chem Eng J 412:128498. https://doi.org/10.1016/j.cej.2021.128498

Zhang C, Liu N, Ming J et al (2022) Development of a novel solar energy controllable Linear fresnel photoreactor (LFP) for highefficiency photocatalytic wastewater treatment under actual weather. Water Res 208:117880. https://doi.org/10.1016/j.watres. 2021.117880

Zhang HL, Baeyens J, Degrève J, Cacères G (2013) Concentrated solar power plants: review and design methodology. Renew Sustain Energy Rev 22:466-481. https://doi.org/10.1016/j.rser.2013.01. 032

Zhang Y, Xiong M, Sun A et al (2021) MIL-101(Fe) nanodot-induced improvement of adsorption and photocatalytic activity of carbon fiber/TiO2-based weavable photocatalyst for removing pharmaceutical pollutants. J Clean Prod 290:125782. https://doi.org/10. 1016/j.jclepro.2021.125782

Zhao H, Li G, Tian F et al (2019a) g-C 3 N 4 surface-decorated Bi 2 $\mathrm{O} 2 \mathrm{CO} 3$ for improved photocatalytic performance : theoretical calculation and photodegradation of antibiotics in actual water matrix. Chem Eng J 366:468-479. https://doi.org/10.1016/j.cej. 2019.02.088

Zhao L, Bhatia B, Yang S et al (2019b) Harnessing heat beyond 200 ${ }^{\circ} \mathrm{C}$ from unconcentrated sunlight with nonevacuated transparent aerogels. ACS Nano 13:7508-7516. https://doi.org/10.1021/ acsnano.9b02976

Zhao Q, Yi XH, Wang CC et al (2022) Photocatalytic Cr(VI) reduction over MIL-101(Fe)-NH2 immobilized on alumina substrate: from batch test to continuous operation. Chem Eng J 429:132497. https://doi.org/10.1016/j.cej.2021.132497

Zhou H, Qu W, Wu M et al (2022) Synthesis of novel BiOBr/Bio-veins composite for photocatalytic degradation of pollutants under visible-light. Surf Interfaces 28:101668. https://doi.org/10.1016/j. surfin.2021.101668

Zhu Y, Xu T, Zhao D et al (2021) Adsorption and solid-phase photocatalytic degradation of perfluorooctane sulfonate in water using gallium-doped carbon-modified titanate nanotubes. Chem Eng J 421:129676. https://doi.org/10.1016/j.cej.2021.129676

Zorainy MY, Gar Alalm M, Kaliaguine S, Boffito DC (2021) Revisiting the MIL-101 metal-organic framework: design, synthesis, modifications, advances, and recent applications. J Mater Chem A 9:22159-22217. https://doi.org/10.1039/D1TA06238G

Publisher's Note Springer Nature remains neutral with regard to jurisdictional claims in published maps and institutional affiliations. 